\title{
La milicia nacional en España (1820-1856)
}

\author{
The National Militia in Spain (1820-1856) \\ Xosé Ramón Veiga ${ }^{1}$ \\ Universidad de Santiago de Compostela, España. \\ https://orcid.org/0000-0003-0775-2582
}

DOI: $h$ ttps://doi.org/10.25032/crh.v6i11.8

Recibido: $31 / 10 / 2020$

Aceptado: $27 / 11 / 2020$

Resumen: La Milicia Nacional, en la España de la primera mitad del XIX, mantuvo una presencia constante en la plaza y en el debate públicos. Pocas instituciones representan tan bien los avatares y la complejidad de la construcción de una cultura de signo político liberal, y su contribución resultó decisiva en la emergencia de la pluralidad característica de la modernidad política. Su conversión en institución armada al servicio del liberalismo progresista, en su día valorada negativamente, se observa hoy como un paso en este sentido y como la muestra de una politización que se desarrolló por carriles muy distintos del unitarismo imaginado por los primeros liberales. En este trabajo se repasa la producción historiográfica generada alrededor del fenómeno miliciano, se analizan las visiones encontradas que mereció de los contemporáneos y se presenta, de forma sintética, el caso de Galicia (NW de España) como ejemplo de la presencia y la actividad de nacionales en zonas escasamente urbanizadas.

Palabras clave: Milicia Nacional; España; Política; Siglo XIX

Abstract: The National Militia, in the Spain of the first half of the 19th century, maintained a constant presence in the square and in the public debate. Few institutions represent so well the vicissitudes and complexity of the construction of a liberal political culture, and their contribution was decisive in the emergence

\footnotetext{
${ }^{1}$ El autor es miembro del grupo de referencia competitiva HISTAGRA (USC).
} 
of the plurality characteristic of political modernity. Its conversion into an armed institution at the service of progressive liberalism, once negatively valued, is today observed as a step in this direction and as the sign of a politicization that developed along paths very different from the Unitarianism imagined by the first liberals. This work reviews the historiographic production generated around the militia phenomenon, analyzes the found visions that it deserved from the contemporaries and presents, in a synthetic way, the case of Galicia (NW of Spain) as an example of the presence and activity of nationals in scarcely urbanized areas.

Keywords: National Militia; Spain; Politics; 19th Century

\section{Introducción}

En una primera mitad de siglo rica en debates políticos, pocas instituciones hay que fuesen objeto de más atención y más posturas encontradas que la Milicia Nacional en sus diferentes versiones de Milicia Urbana o Guardia Nacional. En las Cortes, en la prensa, en las actas municipales, en los comunicados de las autoridades, los milicianos tienen una presencia constante y en aumento, dentro de un debate cada vez más polarizado entre los partidarios de su continuidad reforzada como «guardianes» de la revolución, y los que apuestan por su desaparición, de acuerdo con los nuevos tiempos post de revolución finiquitada que ya no necesitan de ciudadanos armados sino de ley y de orden en manos de cuerpos profesionales y disciplinados. La disputa, en 1844, se salda con la victoria de los segundos y la erección de la Guardia Civil, pero el proceso tiene una historia anterior y tendrá otra posterior entre 1854 y 1856 y entre 1868 y $1874 .{ }^{2}$

El marqués de Miraflores, acreditado representante del doctrinarismo moderado, define a la Milicia Nacional como «más bien un elemento de constante perturbación que conservador y de orden», como una institución anárquica y «arma de partido» en manos de sus adversarios progresistas. Es, en su pensamiento, una organización «peligrosa» y el «verdadero y solo ejército de las

\footnotetext{
2 De hecho, en los meses anteriores al final del Bienio Progresista (1854-1856), las Cortes discutían una nueva ley de Milicia Nacional (La Oliva, jun. 6, 1856). La institución reaparece en 1868 como Voluntarios de la Libertad.
} 
revoluciones». Su coetáneo Nicolás María Rivero, seguidor en sus inicios del «progreso indefinido» y luego uno de los primeros demócratas, habla de ella, al contrario, como la máxima expresión de los «ciudadanos armados», la «fuerza del pueblo», y busca convertirla en una institución con valor constitucional cuya disolución solo podrían decretar las Cortes. ${ }^{3}$ La misma valoración merece a los editores de El Libre Pontevedrés $(1854,13)$ : en la milicia forman los amantes de la libertad, los hombres honrados y laboriosos, por lo que resulta «la institución más grande, más útil y benéfica». Hay mucho aquí de oposición en blanco y negro, lógica para unos contextos polarizados en una «derecha» y una «izquierda» liberales cada vez más enfrentadas, que encuentran en la institución miliciana un arma arrojadiza que echarse en cara.

En parte, esta herencia ha condicionado su análisis histórico, en ocasiones excesivamente apegado tanto a las auto representaciones laudatorias heredadas de los propios milicianos, ${ }^{4}$ como a su vertiente contraria de los que en su día la denigraron en cuanto paradigma de la revolución y la anarquía, una imagen que no dejó de proyectarse hacia delante para explicar situaciones habidas muchas décadas después en el seno de una sociedad completamente diferente.5 $\mathrm{Se}$ impone, por lo tanto, un sano distanciamiento analítico, que intente situar la cuestión en unos términos más apegados a la investigación y a la documentación que a las ideas previas que sobrevuelan el tema. Solo así será posible que nos acerquemos al impacto histórico de la institución miliciana en la construcción de la cultura política liberal y, por extensión, en el proceso de politización y de socialización de la política habido en la España de la primera mitad del siglo XIX. Este es el interés que guía las siguientes páginas.

\section{Estado de la cuestión}

3 Marqués de Miraflores, Reseña histórico-crítica de la participación de los partidos políticos en los sucesos políticos de España en el siglo XIX. (Madrid: Espinosa, 1863), 53, 168; Memorias del reinado de Isabel II. (Madrid: Atlas, 1964, III), 29, 70; Diario de Sesiones de las Cortes Constituyentes, en. 26, 1855 y jun. 14, 1855 .

${ }^{4}$ Historia de la Milicia Nacional. (Madrid: Benito Hortelano y Cía., 1845); Joaquín Ruiz de Morales, Historia de la Milicia Nacional, desde su creación hasta nuestros días. (Madrid: Repullés, 1855).

5 La milicia ciudadana de Vitoria. (Vitoria: Marquínez, 1937); Milicia Popular: diario del $5 \cdot^{\circ}$ Regimiento, 1936-1937. (Barcelona: Hacer, 1977). 
En un trabajo reciente, Álvaro París hace una sugerente aproximación a algunos de los temas claves que informan la Milicia Nacional en el Trienio Liberal (París, 2020, 213-237). El esfuerzo forma parte de un interés renovado por la institución situado en el marco del Bicentenario, pero también en un contexto más amplio preocupado por discernir cómo, a partir de qué condicionantes y con qué resultados se desarrolla, desde 1808, la entrada de España en la modernidad política, en ese nuevo campo de juego abierto a partir de 1789, una partida marcada por la relación dialéctica con las formas de la política tradicional y también con esa otra alternativa de modernidad política paradójica que supone la contrarrevolución, todo dentro de un mix complejo en el que la descente de la política se combina con la fuerza ascendente de unas respuestas populares que, a partir de herramientas políticas propias, reaccionan ante los embates de la modernidad y contribuyen también a configurarla. ${ }^{6}$

Como con otras creaciones nacidas en el Cádiz de las Cortes, la Milicia Nacional pasa del papel a la realidad a partir de 1820 con el Trienio Liberal (Rújula y Chust, 2020). En su trabajo de 1978 sobre los nacionales madrileños, Pérez Garzón daba cuenta de su caracterización social dentro de un marco analítico deudor del concepto de revolución burguesa, con un marcado interés por la identificación del oficio de unos milicianos imaginados como la espina dorsal de una revolución que solo la posterior «traición de la burguesía» habría desviado de su misión histórica. Con un enfoque más político, más deudor del

\footnotetext{
${ }^{6}$ Isabel Burdiel, «Morir de éxito: el péndulo liberal y la revolución española del siglo XIX», Historia y Política.1 (1999): 181-203; Jesús Millán y María Cruz Romeo, «Was the liberal revolution important to modern Spain? Political cultures and citizenship in Spanish history», Social History.29-3 (2004): 284-300; «La naissance de la politique moderne en Espagne (milieu XVIII siècle-milieu XIX siècle)», Mélanges de la Casa de Velázquez (Dossier).35-1 (2005); Martyn Lyons, Post-Revolutionary Europe, 1815-1856. (Houndmills: Palgrave MacMillan, 2006); Josep Fontana, La época del liberalismo. (Barcelona: Crítica-Marcial Pons, 2007); Jean-Philippe Luis, «Cuestiones sobre el origen de la modernidad política en España (finales del XVIII-1868)», Revista de historia Jerónimo Zurita.84 (2009): 247-278; Javier Fernández Sebastián, coord., La aurora de la libertad. Los primeros liberalismos en el mundo iberoamericano. (Madrid: Marcial Pons, 2012); Emilio La Parra et al. El nacimiento de la política en España (1808-1869). (Madrid: Editorial Pablo Iglesias, 2012); "Democracia y mundo rural en España», Ayer (Dossier).89 (2013); Salvador Calatayud, Jesús Millán y María Cruz Romeo, eds. Estado y periferias en la España del siglo XIX. Nuevos enfoques. (València: PUV, 2009); El Estado desde la sociedad. Espacios de poder en la España del siglo XIX (Alacant: Universitat, 2016); Jesús Millán, «La formación de la España contemporánea: el agotamiento explicativo del fracaso liberal», Ayer. 98 (2015): 243-256; Jorge Luengo, «La formación de la sociedad civil en la España del siglo XIX». Pensar el poder. Liber amicorum de Pedro Carasa. Eds. Bartolomé Yun y Jorge Luengo (València: PUV, 2018), 77-96; Michael Freeden, Javier Fernández Sebastián y Jörn Leonhard, eds. In Search of European Liberalisms. Concepts, Languages, Ideologies. (New York: Berghahn Books, 2019).
} 
interés por la difusión de un ideario liberal y revolucionario, aparece apenas unos años antes la seminal investigación de Gil Novales sobre las sociedades patrióticas, espacios de una inicial esfera pública que Habermas teorizara en su libro de 1962, Strukturwandel der Öffentlichkeit (Pérez Garzón, 1978; Gil Novales, 1975). Juntos conforman los pilares a partir de los que avanzará la investigación sobre la institución miliciana, aunque los frutos sean más bien tardíos y, como ocurre con todos los inicios brillantes, no siempre a la altura de unos precedentes tan llenos de sugerencias como académicamente exigentes en el seguimiento de su estela.

No tiene mayor interés presentar de forma detallada una relación de trabajos sobre la Milicia Nacional en sus diferentes versiones, que por otro lado sería siempre incompleta porque muchas de las investigaciones, al igual que la propia Milicia, han encontrado su acomodo en espacios locales y en publicaciones de difusión escasa y consulta difícil.7 De manera general, las aportaciones han seguido la derrota marcada por el libro de Pérez Garzón y eso redunda en publicaciones, en su mayoría, más atentas a la definición social de la Milicia que al estudio de sus componentes políticos, más centradas en la caracterización socioeconómica de mandos y milicianos y en su ubicación dentro de la naciente sociedad de clases, que en el estudio de sus derivadas políticas, en especial su papel como marco de desarrollo de una cultura política liberal que aspira a trascender las fronteras milicianas y expandirse por el resto de la población. No se trata de una limitación o de una cortedad de miras de estos estudios, sino de su adecuación a las preguntas que los historiadores dirigen entonces a la institución miliciana. Eran tiempos más sociales que políticos o culturales, y de

\footnotetext{
7 Ejemplos de estos trabajos, tan interesantes como a menudo desconocidos: Francisco Santos, «La Ribera tudelana durante la Primera Guerra Carlista (1833-1839). El funcionamiento de la Milicia Urbana», Revista del Centro de Estudios Merindad de Tudela.6 (1994): 79-94; Luis F. Palma, «La Milicia Nacional de Lucena en el Trienio Esparterista», Crónica de Córdoba y sus pueblos.13 (2007): 323-338; Manuel Domínguez, «Salvación, unión e fraternidade: a Milicia Nacional de Pontedeume (1834-1844)», Cátedra. Revista eumesa de estudios.25 (2018): 299332; José Antonio Ramón, «La Milicia Nacional de Fornela durante el Trienio Progresista (18401843)», Estudios Bercianos.39 (2015): 149-165; Luis F. Peñalver, «La revolución de 1854 y la formación de la Milicia Nacional. Talavera en el Bienio Progresista», Cuaderna.16-17 (2008-9): 77-116; Miguel Ángel Naranjo, «La Milicia Nacional de Almendralejo», Revista de Estudios Extremeños.72 (2016): 639-684. El grado de relevancia y de aportación de estas investigaciones locales (que no localistas), está directamente ligado a su conexión con los temas centrales que definen la temática miliciana, así como a su capacidad para integrar las conclusiones en el panorama general.
} 
ahí la orientación seguida. La discusión, un tanto bizantina y circular, sobre el sí o el no de la revolución burguesa en España sobrevuela las iniciativas investigadoras y ha condicionado su desarrollo hasta hace, relativamente, poco tiempo.

Con la injusticia y la subjetividad que siempre acompaña este tipo de relaciones, cabe destacar el trabajo de Chust para Valencia (lástima de una cronología circunscrita a 1834-1840) y las investigaciones centradas en poblaciones catalanas, que tienen la virtud de estudiar la Milicia Nacional no únicamente en las capitales de las recién creadas provincias, sino en poblaciones de menor fuste que serán focos de contagio liberal en el territorio, un aspecto central porque la milicia será uno de los vectores básicos de penetración infraestructural del nuevo ideario. ${ }^{8}$ Por otro lado, y aunque el tema merezca más estudios de los habidos, hay que señalar que la diferenciación rural-urbano para la primera mitad del siglo XIX resulta poco operativa si por tal se entienden espacios cerrados y bien separados, porque la realidad se ajusta más a una visión interconectada, de fronteras porosas y contactos más estrechos de lo que podría pensarse a partir de un enfoque de compartimentos estancos (Caballero y Romero, 2006). Lo veremos en la tercera parte de este artículo. Mención aparte merece la investigación de Herrero sobre la milicia pamplonica, tanto por su ambición cronológica como temática, con una visión al tiempo social y política de la institución, además de por analizar un caso poco habitual de milicianos nada liberales hasta el verano de 1822 en contraste con unas tropas imbuidas de sentimiento liberal. La reciente reflexión de Aquillué camina precisamente en la

${ }^{8}$ Manuel Chust, Ciudadanos en armas: la Milicia Nacional en el País Valenciano (1834-1840). (València: Alfons el Magnànim, 1987); Robert Vallverdú, El suport de la Milícia Nacional a la revolució burgesa a Reus (1793-1876). (Reus: AER, 1989); F. X. Sánchez, «La Milícia Nacional d'Alcover durant el Trienni Liberal (1820-1823)», Butlletí del Centre d'Estudis Alcoverencs.78 (1997): 37-46; María Carmen Capdevila y Quintí Casals, «Artesanos y campesinos en la Milicia Nacional de Lleida en la primera mitad del Ochocientos». Campesinos, artesanos, trabajadores. Coords. Santiago Castillo y Roberto Fernández (Lleida: Milenio, 2001), 435-450; Joan Portet, La Milícia Nacional de Vic durant la primera guerra carlina. (Vic: PEO, 2003); Francisco Dueñas, La Milicia Nacional Local en Barcelona durante el Trienio Liberal (1820-1823). (Tesis doctoral: UAB, 1997); Antoni Sánchez Carcelén, «La formación de la Milicia Nacional en Lleida (18201821)», Cuadernos de Historia Contemporánea.3o (2008): 251-271; Quintí Casals, «Milicia Nacional, liberalismo y progresismo. El prototipo leridano en los primeros dos tercios del siglo XIX», Trienio.35 (2000): 117-154; Manuel Santirso, «Voluntarios realistas, voluntarios de Isabel II y milicia nacional, o en la guerra también hay clases (Cataluña, 1832-1837)», Historia Social.23 (1995): 21-40; Ramón Arnabat, La revolució de 1820 i el Trienni Liberal a Catalunya. (Vic: Eumo, 2001); Jordi Roca, La Barcelona revolucionària $i$ liberal: exaltats, milicians $i$ conspiradors. (Barcelona: Fundació Noguera, 2011). 
dirección de valorar la aportación de los nacionales al proceso de politización popular en la España anterior a 1840, fundamentalmente en su vertiente progresista y tendencialmente demócrata, una hipótesis que también se defiende aquí.9

Son ya muchas las capitales de provincia que disponen de una monografía de su Milicia Nacional, y sin duda merecedoras de un trabajo que sintetice los resultados obtenidos, pero que no podemos ofrecer por razones de espacio. ${ }^{10}$ Cualquier intento de puesta en común choca con la realidad de investigaciones que no responden a un patrón común ni comparten unas mismas bases teóricas y metodológicas, por no hablar de que los interrogantes que las guían son también heterogéneos. Al tratarse de trabajos situados en una franja temporal muy amplia y transitar por diferentes tradiciones historiográficas, resultan en una amalgama variopinta que no facilita ni la comparación ni la búsqueda de denominadores comunes. Se trata, además, de aportaciones que se refieren a tramos cronológicos muy diversos, desde las que solo lo hacen con la Milicia del Trienio Liberal, hasta las que (son las menos) arrancan de su nacimiento legal en el Cádiz de las Cortes y llegan a su postrera aparición con los Voluntarios de la República de 1873, pasando por todas las combinaciones posibles entre ambas fechas. La misma variabilidad legal y terminológica de la Nacional no favorece tampoco la síntesis. ${ }^{11}$

9 Guillermo Herrero, Liberalismo y Milicia Nacional en Pamplona durante el siglo XIX. (Pamplona: UPN, 2003); Daniel Aquillué, «La milicia democrática, 1834-1840». Pensar con la Historia desde el siglo XXI. Eds. Pilar Folguera et al. (Madrid: UAM, 2015), 3025-3041. También, Manuel Albargonzález, La Milicia Nacional: protagonista y víctima de la revolución liberal en España (1834-1837). (Trabajo Fin de Máster: UAM, 2015).

10 Rosa Ana Gutiérrez y Rafael Zurita, «El Trienio Constitucional y la organización de la Milicia Nacional en Alicante (1820-1823)». La revolució francesa i el procés revolucionari a Catalunya i al País Valencià (Barcelona: UAB, 1999), 99-114; Antonio Guillén, Una aproximación al Trienio Liberal en Almería. La Milicia Nacional Voluntaria y su entorno (1820-1823). (Almería: IEA, 2000); Óscar González, «Hechos de la Milicia Nacional leonesa (1820-1823)». Las guerras en el primer tercio del siglo XIX en España y América, II. Coord. Paulino Castañeda (Madrid: Deimos, 2005), 99-118; Miguel Ángel Naranjo, La Milicia Nacional de la ciudad de Badajoz y su marco provincial hasta su disolución de 1844. (Badajoz: Diputación, 2008); José María García León, La Milicia Nacional de Cádiz durante el Trienio Liberal, 1820-1823. (Cádiz: Caja de Ahorros, 1983); Baldomero Hernández, La Milicia Nacional y las quintas en Mahón durante el Trienio Liberal. (Es Castel: Museo Militar de Menorca y Patrimonio Histórico-Militar, 2009); Claudio Calles, La Milicia Nacional en Salamanca durante el Trienio Liberal (1820-1823). (Tesis doctoral: Universidad de Salamanca, 2015); Mario Ureña, Regulación jurídica de la Milicia Nacional y su implementación en Castellón. (Tesis doctoral: UNED, 2004); Luis Sorando y Antonio Manzano, «La Milicia Nacional de Zaragoza (1820-1823)», Emblemata.6 (2000): 177-212

${ }^{11}$ Los gallegos tenemos una expresión que recoge bien esta situación: «Vender a vaca a ramal tirado», que se puede traducir, con libertad filológica, en adentrase en un tema y luego ver qué 
Siempre de forma general y con las particularidades lógicas de cada caso, hay una serie de elementos compartidos que definen a la institución desde sus orígenes y que le otorgan solidez como objeto de análisis histórico. La más obvia es su caracterización de civiles armados en defensa, en general, de la legalidad constitucional, sea la de 1812, la de 1837 o la de 1869, con la excepción del período entre finales de 1833 y el verano de 1836, en que su actividad se justifica en la lucha a favor de la continuidad dinástica en la persona de la hija de Fernando VII, la reina-niña Isabel II tutelada por su madre, la entonces «idolatrada» Cristina. ${ }^{12}$ En ese tiempo los milicianos no portan bandera constitucional alguna sino que responden al apelativo de «cristinos» o «isabelinos», pero la situación enseguida cambiará.

También de manera general, su dependencia jerárquica recae en los ayuntamientos, los encargados de organizar la recluta (voluntaria o forzosa, según el caso) y de financiar los costes. Sin embargo, y con variaciones según el contexto, la responsabilidad última se sitúa en los mandos del ejército (sobre todo en 1834-1839), en los jefes políticos/gobernadores civiles y en las diputaciones provinciales. En primera instancia, por lo tanto, las decisiones respecto de los nacionales competen a los concejos, pero la palabra definitiva suele corresponder a instancias o bien diferentes (el ejército) o bien jerárquicamente superiores. Con todo, lo más notable es esta caracterización local, que convierte a las compañías en agrupaciones difíciles de manejar con criterios ordenancistas por su bajo nivel de centralización. Al final, este será uno de los argumentos esgrimidos en el primero de sus apagones, el de 1844 (al tiempo, significativamente, que se crea la Guardia Civil, un cuerpo semimilitarizado, jerarquizado, de obediencia vertical y alejado de toda dependencia concejil).

pasa, sin seguridad respecto de los resultados. Agradezco al etnólogo aficionado Miguel Paz el haberme aportado esta referencia.

12 «Idolatrada CRISTINA»; «hermosa, celestial y siempre liberal Cristina»; «inmortal CRISTINA»; «tierna madre idolatrada», «beldad clemente»... Ver: Manuel María Cid, Discurso que en la solemnidad de la jura y bendición de la bandera del Batallón de la benemérita Milicia Nacional de Santiago pronunció... (Santiago de Compostela: Fermín Campaña, 1837), 10; Relación de los festejos con que el Primer Batallón de la Milicia Urbana de La Coruña celebra la bendición de su bandera... (A Coruña: Boletín Provincial, 1834), 10; José del Castillo, Exclamaciones de un expatriado. (Barcelona: Ramón Martín, 1833), 6, 55; Al Estatuto Real (Santiago de Compostela, ab. 21, 1834). 
La Milicia nace como una institución urbana y dedicada a tareas de mantenimiento del orden y la ley en territorios bien delimitados. Su genérica defensa de los principios constitucionales se concreta en la persecución de bandidos y desertores, en la custodia de presos, en el traslado de caudales, en la guarda de quintos, en asegurar la tranquilidad en ferias y mercados, en auxiliar el cobro de las contribuciones, en garantizar el desarrollo de los sorteos para el servicio militar y en la vigilancia de poblaciones, pero las necesidades de cada momento enseguida dejan cortas estas funciones y la metamorfosean en un cuerpo polifuncional y de mayor penetración infraestructural, presente en operaciones bélicas como unidades anexas a las tropas, en acciones fuera de sus localidades de referencia (las milicias activas y movibles, con voluntarios pagados: los «peseteros») y con compañías que también surgen en zonas rurales, en un intento de garantizar la seguridad en las áreas del territorio a las que el ejército no llega y de llevar hasta el último rincón el espíritu miliciano, la idea del liberal comprometido que dedica una parte de su tiempo a garantizar los principios constitucionales. Su presencia debería de servir como recordatorio de que un nuevo estado, liberal, está en construcción, de que cuenta con apoyos locales y de que en su ejecución precisa del papel activo de todos sus gobernados. Por aquí queda todavía mucho que trabajar a partir de investigaciones acotadas espacialmente, pero de amplio radio cronológico, que permitan constatar la presencia de tendencias a largo plazo políticamente relevantes.

La recluta de efectivos siempre va a ser un problema. Como decía el gobernador civil de Lugo en 1875, huir del «servicio al rey», de la obligación de dedicar tiempo y esfuerzos al servicio armado, está en el ADN de las poblaciones. ${ }^{13}$ Las cifras de prófugos del servicio militar, de los que hacen enormes esfuerzos por redimir su suerte de soldado y de los que desertan, están ahí y son muy significativas. ${ }^{14}$ Nada de extraño, por lo tanto, que esta misma realidad afecte a la

13 Antonio de Medina al alcalde de Ribadeo (Lugo), mar. 16, 1875. Arquivo Municipal de Ribadeo (AMR), Correspondencia, legajo 1132. Lo mismo afirmaba, en 1822, su homónimo Ángel del Arenal: la población es «desafecta por instinto al servicio de las armas» (Gobierno político de la provincia de Lugo, mar. 8, 1822).

${ }_{14}$ Xesús Balboa, «Quintos e prófugos: os galegos e o servicio militar no século XIX». Mentalidades colectivas e ideoloxías. Eds. Xavier Castro y Jesús de Juana (Ourense: Deputación, 1991), 51-71; José Ramón Urquijo, «¿Voluntarios o quintos? Reclutamiento y deserción en la primera Guerra Carlista». Violencias fratricidas. Carlistas y liberales en el siglo XIX. (Pamplona: Príncipe de Viana, 2009), 99-186; Albino Feijoo, Quintas y protesta social en el siglo XIX. (Madrid: Ministerio de Defensa, 1996); Valentina Fernández Vargas, Sangre o dinero. El mito del ejército nacional. 
Milicia Nacional. Servir en estos cuerpos, es cierto, no es lo mismo que hacerlo como soldado en el ejército o como quintado en el servicio militar, pero detrae un tiempo que se requiere en otros menesteres, resulta arriesgado y deja una indeleble marca política como «negro», como liberal ante una comunidad local signada por el interconocimiento y en la que todos saben de todos. Un cambio en las tornas políticas (por ejemplo, el habido en 1823 o en 1843) puede tener consecuencias nefastas si uno no dispone de profilácticos sociales y económicos.

Las quejas de ayuntamientos, diputaciones y jefes políticos porque la población intenta rehuir el servicio como nacionales, se repiten en la documentación, pero hay que situarlas en su contexto para no hacer de ellas un signo de repudio de la Nacional y de lo que significaba servir en ella. De hecho, la lectura puede ser la contraria: valorar en lo que vale el servicio voluntario, y también el forzoso en la milicia nacional local o «de la ley», porque supone riesgos elevados y tiene un importante coste de oportunidad. El tiempo, y no digamos la propia existencia, son recursos perecederos que conviene cuidar. Hacer guardias en puertas y murallas, perfeccionar las maniobras en los días festivos, custodiar cárceles y presos, realizar rondas nocturnas, salir en busca de ladrones y prófugos y pelear contra los carlistas, merecen pensarlo dos veces antes de anotarse voluntario e intentar evitar la asignación forzosa, pero también que los historiadores valoremos con justicia interpretativa lo que supuso ser miliciano nacional.

Si la recluta nunca viajó por railes engrasados, financiar la milicia resultó un constante quebradero de cabeza, máxime en un estado como el español decimonónico en números rojos, los mismos que exhiben unos ayuntamientos sobrecargados de exigencias. De las escuálidas arcas municipales salen los reales que pagan uniformes a los alistados sin recursos, y también los destinados a compensar las salidas fuera de la localidad. Los tambores de las compañías, o los instrumentos de la banda de música, hay también que financiarlos, y en conjunto suponen gastos quizás no elevados en su montante pero proporcionalmente de muy difícil asunción para las tesorerías locales. El armamento, munición y demás

(Madrid: Alianza, 2004); Beatriz Frieyro, Guerra, ejército y sociedad en el nacimiento de la España contemporánea. (Madrid: Alianza, 2009). 
atrezo bélico llegaba del ejército o, en todo caso, lo proporcionaban instancias superiores. Casi siempre escaso, antiguo, de mala calidad, variopinto en su configuración y muchas veces necesitado de arreglos cuyos costes recaían en las corporaciones locales. Los exceptuados legalmente de la recluta debían pagar una cantidad mensual (entre 5 y 50 rs.) que ayudaba en el financiamiento, pero su cobro siempre fue difícil, sujeto a las reclamaciones de los pagadores y, en última instancia, dependiente de la voluntad de los ayuntamientos de cara a su milicia, que no siempre fue la mejor.

Armar a los milicianos resultó una decisión controvertida. En la teoría de la cultura política liberal el ciudadano debe contar con un fusil para defender el orden constitucional, pero en la práctica el tema se complica. La deseada unanimidad de pareceres, la anhelada unidad del pueblo liberal alrededor de unos presupuestos ideológicos, se demuestra imposible, una utopía que la dinámica histórica enseguida deshace por más que, como aspiración, se mantenga y dificulte la asunción del pluralismo como virtud y no como división inaceptable. Las polémicas sobre el carácter voluntario o forzoso de la Milicia pasan por aquí, porque la experiencia demuestra que dar armas a una agrupación que integre, sin distingos, a los varones entre 18 y 45 años (las edades varían en función de la legislación aplicable) es, como mínimo, aventurado, porque fácilmente pueden volverse en contra de los propios liberales.

Las divisiones en su seno, además, avivan la polémica, con unos moderados que buscan confiarlas a los que, social y económicamente, tienen «algo que perder», frente a los más exaltados que desean armar al «pueblo» para profundizar en la revolución, derrotar a sus enemigos e incluso, ocasionalmente, hacer frente al ejército cuando intenta frenarla o revertirla. Se supone que el miliciano usará bien las armas que el Estado le confía, pero la realidad es tan plural que esto no pasará de una entelequia: se usarán contra realistas y carlistas, contra bandidos y prófugos, sí, pero también contra gobiernos elegidos en las urnas (en 1835 o 1836), contra tropas del ejército (en 1822, en 1840 o en 1843), contra la población «amotinada» y, en el sumun de la paradoja, contra los propios milicianos por parte de aquellos pasados a la «facción» carlista. Si definir quién debía gozar del derecho de sufragio fue uno de los asuntos que más contribuyó a la división de los liberales (Sierra, Peña y Zurita 2020), determinar quiénes 
debían armarse lo hizo en igual o superior grado, porque las papeletas no matan, pero los fusiles sí. La dimensión y trascendencia políticas del hecho de portar armas legalmente tiene connotaciones muy hondas en la creación de la identidad política, y también en este caso las distancias entre moderados, progresistas y demócratas se harán patentes y dificultarán una visión unitaria y compartida sobre la viabilidad y la utilidad de la ciudadanía en armas y, más allá, de la misma violencia revolucionaria, entendida por algunos como necesaria frente a poblaciones «políticamente inmaduras» o contra gobiernos que conculcan las bases constitutivas de la misma filosofía liberal. ${ }^{15}$

Son innumerables las leyes, ordenanzas y reglamentos promulgados para introducir orden en la Milicia Nacional que, por primera vez, se define en la Constitución de 1812 (Pérez Garzón). Esta variabilidad es el mejor índice para calibrar las diferentes visiones políticas sobre lo que debería ser la agrupación, con un grado de apertura social, económico y político muy variable. Voluntaria o forzosa, con más o menos exceptuados, con uniforme o sin él, pagado por los alistados o por los ayuntamientos, con un grado variable de apertura democrática en la elección de los oficiales por los milicianos, con una dependencia oscilante respecto de otras instancias, local o movible. En realidad, más que de una habría que hablar de diferentes milicias según la legalidad que las ampara. Poco tiene que ver la Milicia Urbana de 1834 con su homónima Nacional de 1842 (una dimensión temporal y contextual que nunca se debe perder de vista), no solo porque su reglamentación es distinta sino porque su composición y su grado de compromiso político también lo son. Además, y para añadir complejidad, resulta que con independencia de las disposiciones legales, al final son las entidades locales y, si acaso, el comandante militar de turno, los decisivos en la configuración miliciana, porque su grado de autonomía respecto de otras instancias les permite configurarla a su antojo según gustos y preferencias. Por esto a partir de una misma reglamentación en unos lugares la recluta es amplia y generosa y en otros restringida.

De lo que no cabe duda alguna es de que la Milicia, quizás más de lo

15 Caso de los voluntarios nacionales en la Barcelona del Trienio Liberal (Roca, La Barcelona) o, fuera ya de nuestro estudio, de los voluntarios de la libertad republicanos alzados en 1869 contra el gobierno monárquico. 
deseado por sus mentores intelectuales, interviene en política. Lo hace en el centro del sistema, en ese Madrid capitalino con unos nacionales presentes en todos cuantos acontecimientos suceden, pero igualmente en las capitales de provincia, en las villas cabeza de partido judicial y en ayuntamientos de menor porte y caracterización rural. No hay vaivén político en que no figure: lo hace en el Trienio Liberal de 1820-1823 (con el 7 de julio de 1822 como su particular epifanía y su carta de presentación pública, rápidamente convertida en fecha de memoria), en la (escasa) lucha contra los invasores franceses de 1823, en las revoluciones veraniegas de 1835 y 1836 , en la que da paso al Trienio Esparterista (y también en su caída en 1843) y, en fin, en las revueltas aguas políticas del Bienio Progresista (1854-1856) y del Sexenio Democrático (1868-1874).

Pero más allá de esta inmersión en los grandes acontecimientos, conviene destacar su papel en la vida política cotidiana de miles de ayuntamientos, que solo una mayor densidad de investigaciones podrá calibrar en su justa medida. Aquí los milicianos hacen política en la plaza, firman manifiestos, se dirigen con protestas o peticiones a las corporaciones locales, apoyan determinados candidatos, influyen en los procesos electorales, auxilian o resisten los golpes militares habidos en las capitales, condicionan las políticas impulsadas desde los consistorios, empujan a favor de la exclaustración monástica y de los repartos de tierras de propios... ${ }^{16}$ En definitiva, nada de lo político les resulta ajeno, y por eso en el análisis de las complejidades de la vida política local su consideración es obligada, aunque solo sea porque muchos de los políticos en activo pertenecen o han pertenecido a la Nacional. Es más: las purgas que se producen entre los alistados por los alcaldes y concejales que ocupan las corporaciones, resultan la mejor muestra de su politización, porque más allá de que reúnan las condiciones para su ingreso, son factores relacionados con fidelidades ideológicas y clientelares los que actúan en la base de la criba. Con todo, faltan trabajos que establezcan con precisión y atención a la cronología las relaciones políticas entre las agrupaciones milicianas y el poder local, así como el peso concreto que la configuración miliciana pudo tener en la definición de tendencias políticas

${ }^{16}$ Esta influencia en la vida política local la recoge con claridad el gobernador civil de Ourense en 1855, al prohibir a los milicianos acudir «en cuerpo» depositar su voto para así «alejar ideas de intimidación o de que pueda suponerse obran cohibidos por sus jefes»: Boletín Oficial de la Provincia de Orense (nov. 13, 1855). 
significativas, como mínimo, entre 1820 y 1874 .

Los milicianos se politizan y también se nacionalizan. El proceso de «creación» de españoles ha recibido mucha atención en estos años a partir de la propuesta seminal de Borja de Riquer. ${ }^{17}$ Aunque pueda resultar paradójico dada su dependencia concejil, varios aspectos de la Milicia pueden haber facilitado la nacionalización de sus integrantes, en la estela de los impulsos nacionalizadores generados a partir de las regiones y «pequeñas patrias» (Núñez et al., 2006). De un lado, su apellido ( «Nacional»), que más allá de resonancias obvias sitúa a sus integrantes dentro de una agrupación distribuida por todos los rincones de un territorio contemplado como nacional y que se desea nacionalizado. La jura que realizan los milicianos, igual en todo el país, la bandera bicolor que los acoge, el compartir un mismo reglamento, los hace partícipes de una solidaridad de grupo que trasciende sus concretos espacios locales, a sus identificaciones comunitarias inmediatas para integrarlos en la gran familia miliciana. La lucha contra un enemigo común, en especial esos carlistas siempre «malos» españoles e «hijos espurios» de la madre patria, camina en igual dirección, y ya se sabe que nada une más que un buen opositor. Estamos ante un nacionalismo de confrontación que, sin embargo, tiene una pega importante y que merecería ser objeto de estudios: la propaganda puede vender al enemigo como español desnaturalizado, pero resulta que no pocas veces este se personifica en el vecino unido a la facción, y una vez finalizada la lucha no resulta fácil ver y sentir como connacional al que ha fusilado, troceado el cuerpo y colgado en picas al hijo, al padre o al hermano.

Los desfiles, las paradas, las formaciones, los himnos patrióticos entonados, las músicas de la banda del regimiento, las escarapelas, las invocaciones a morir por la constitución, la patria y la reina, los discursos de los mandos plenos de nacionalismo español, la convivencia en las trincheras con soldados y milicianos llegados de otras zonas del territorio patrio, las salidas de

17 Borja de Riquer, «Nacionalidades y regiones. Problemas y líneas de investigación en torno a la débil nacionalización española del siglo XIX». La Historia Contemporánea en España. Eds. Antonio Morales y Mariano Esteban (Salamanca: Universidad, 1996), 73-92. La bibliografía disponible es casi inabarcable. La línea de investigación más sólida y continuada está recogida en las actas de los varios congresos dedicados al tema. Ver, Mariano Esteban, «El proceso de nacionalización española. Balance aproximativo de un proyecto». La nación omnipresente. Procesos de nacionalización en la España contemporánea. Eds. Justo Beramendi, Miguel Cabo, Lourenzo Fernández y Alfonso Iglesias (Granada: Comares, 2020), IX-XXIV. 
la milicia movible fuera de las fronteras locales, provinciales y hasta regionales, el pisar y luchar por territorios nunca visitados que ahora se descubren como propios, como nacionales... todo contribuye a crear en estos varones un sentimiento de pertenencia más allá de las solidaridades locales, visible en algunas memorias más o menos estereotipadas. Lo que todavía nos faltan son análisis de milicianos de a pie que permitan constatar, en efecto, esta asunción de una nueva (o reforzada) identidad nacional.

Para finalizar este repaso, obviamente incompleto, por algunos de los elementos comunes en los estudios sobre la Milicia Nacional, es necesario mencionar dos de los aspectos mejor trabajados por la historiografía. De un lado, su progresiva radicalización hacia el ala situada más a la izquierda del liberalismo, visible en especial en sus reapariciones de 1854 y 1868, pero que arranca de atrás. De fuerza armada civil del liberalismo pasa a serlo únicamente de sus versiones progresista, demócrata y, cada vez más, tendencialmente republicana. De otro lado, la caracterización social de sus integrantes, el aspecto al que los investigadores han dedicado mayores esfuerzos, sin duda por esa marca de origen de ser la Milicia uno de los pilares de la revolución burguesa. Aquí los análisis se resienten de la falta de una definición unívoca de la categoría burguesía y, en general, de un mínimo consenso sobre qué considerar clases populares, clases medias, burguesía, etcétera, así como del uso de clasificaciones variadas que dificultan la comparación, de forma que si para unos el pequeño comercio puede asimilarse a esa nebulosa burguesa, para otros debe hacerlo en el amplio compartimento de los grupos populares. En cualquier caso, y siempre con las imprescindibles precauciones, algunas conclusiones pueden presentarse.

La primera es que las agrupaciones milicianas solo reflejan parcialmente las divisiones sociales de las localidades en que surgen, con tendencia a la sobrerrepresentación de los grupos acomodados y una merma proporcional de los populares. Por más que artesanos, tenderos, empleados en fábricas y talleres o labradores, marineros y jornaleros figuren entre sus filas, su presencia suele ser proporcionalmente menor a la que tienen en las sociedades de que surgen compañías y batallones. La Nacional no es asimilable al ejército, donde sí existe una correspondencia entre la caracterización social de los soldados y las divisiones sociales que marcan las poblaciones donde se reclutan. El carácter 
burgués, en definitiva, destaca sobre el propiamente popular, aunque es cierto que esta afirmación incluye casos que pueden invalidarla o matizarla según la caracterización social de los espacios estudiados. Una vez dicho esto, y como segunda conclusión, conviene añadir de inmediato que no puede presentarse a la Milicia como un coto integrado por burgueses o categorías asimilables a la burguesía, y esto tanto para el caso de los voluntarios como, sobre todo y evidentemente, para los forzosos. Por razones variadas y no solo ideológicas (prestigio, búsqueda de notoriedad, currículum político, ventajas en la distribución de tierras o en el acceso a cargos, evitar el pago de pensiones, disponer de armas...), el alistamiento cubrió un amplio espectro social, y en algunos casos constituye un índice del arraigo popular de las ideas liberales.

\section{La Milicia Nacional en su lugar: milicianos, escritores y periodistas}

A diferencia de otros temas más ocultos, no resulta difícil encontrar referencias a la Nacional entre la producción escrita de los dos primeros tercios del siglo XIX. En parte, porque algunos de los escritores del momento y muchos de los periodistas también fueron milicianos, y en su cursus honorum nunca ocultaron esta pertenencia por sentirse orgullosos, resultarles provechosa y ser una buena publicidad para su carrera política. Pero sobre todo porque la presencia de la institución fue tan evidente y continuada, tan visible y con tanto protagonismo, que difícilmente podría pasar desapercibida para cualquier observador. Su inmersión en la vida política resultó constante, y por lo tanto en todo repaso contemporáneo a esta siempre hay una mención más o menos amplia a la Nacional. ${ }^{18}$

\footnotetext{
${ }^{18}$ Las referencias posibles son múltiples, y podrían ampliarse a voluntad. Por ejemplo: Historia; Ruiz de Morales; Miraflores, 1863, 1964 y Apuntes histórico-críticos para escribir la Historia de España de la época desde 1820 a 1823. (Londres: Ricardo Taylor, 1834); Antonio Alcalá Galiano, Recuerdos de un anciano. (Madrid: Perlado y Cía., 1913); Historia de las regencias (1833-1843). (Pamplona: Urgoiti, 2008); Estébanez Calderón, Mis memorias. (Madrid: Tebas, 1975); Fernando Fernández de Córdova, Mis memorias íntimas. (Madrid: Sucesores de Rivadeneyra, 1886); Evaristo Escalera y Manuel González, La España del siglo XIX. Sus hombres y acontecimientos más notables. (Madrid: J. J. Martínez, 1864); Ramón Santillán, Memorias (1808-1856). (Madrid: Tecnos, 1996); Francisco Espoz y Mina, Memorias. (Madrid: Rivadeneyra, 1851-2); Luisa Sáenz de Viniegra, Vida del general D. José María Torrijos y Uriarte. (Madrid: Minuesa, 1860); Antonio María García Blanco, Resumen de un siglo. (Osuna: M. Ledesma, 1887); Carlos Dembowski, Dos años en España durante la Guerra Civil, 1838-1840. (Barcelona: Crítica, 2008); Francisco Cabello, Francisco Sta. Cruz y Ramón María Temprado, Historia de la guerra
} 
En lo fundamental, existe un doble rasero, cronológico y valorativo, en las referencias que se pueden encontrar, que de una forma mucho más que simbólica representa la propia evolución interna del liberalismo. Respecto de la actuación miliciana en el Trienio Liberal de 1820-1823 apenas si hay dudas: alabanzas y agradecimientos por su labor, imprescindible para todos excepto, claro, para realistas y antiguos afrancesados en proceso de adaptación al campo cristino, que no liberal. ${ }^{19}$ Estamos en plena revolución, y la Nacional representa la unión de los liberales para acabar con un absolutismo que todavía tiene al soberano entre los suyos, y que debe hacer frente a las guerrillas realistas y a una poderosa alianza exterior contrarrevolucionaria que será decisiva en la destrucción del segundo experimento liberal. La reaparición de finales de 1833 y a lo largo de 1834 contempla una milicia muy restringida socialmente, y además la sobrevuelan

última en Aragón y Valencia. (Zaragoza: «Institución Fernando el Católico», 2006); Mariano Gracia, Memorias de un zaragozano (1850-1861). (Zaragoza: Institución Fernando el Católico, 2013); Antonio Pirala, Historia de la guerra civil y de los partidos liberal y carlista. (Madrid: Mellado, 1856); Eduardo Chao, Historia de la vida militar y política de Martín Zambrano. (Madrid: P. Madoz y L. Sagasti, 1846); Victoriano Ameller y Mariano Castillo, Los mártires de la libertad española. (Madrid: Luis García, 1853); Rosendo M. López Castrillón, Las nueve vidas de la Casa de la Fuente de Riodecoba. Libro de memoria de una casa campesina de Asturias (15501864). (Xixón: Muséu del Pueblu d'Asturies, 2018); Vida militar y política de Espartero. (Madrid: Benito Hortelano y Cía., 1844-5); La España del siglo XIX. Colección de conferencias históricas celebradas durante el curso 1885-6. (Madrid: Antonio San Martín, 1886), 409-441; Fernando Garrido, La España contemporánea. Sus progresos materiales y morales en el siglo XIX. (Barcelona: Salvador Manero, 1865); Leopoldo de Alba, La revolución española en el siglo XIX. (Madrid: Biblioteca Universal Económica, 1869); Antonio I. Cervera, La voluntad nacional, cómo el pueblo espera que la interpreten las Cortes Constituyentes. (Madrid: Tomás Núñez, 1854); Juan Martínez Villergas, Los políticos en camisa. (Madrid: Imprenta del Siglo, 1845-7); Nicomedes-Pastor Díaz, A la Corte y a los partidos. (Madrid: Corrales y Cía., 1846); Miguel Villalba Hervás, Recuerdos de cinco lustros, 1843-1869. (Madrid: La Guirnalda, 1896); Miguel A. Príncipe, Tirios y troyanos. Historia tragi-cómica-política de la España del siglo XIX. (Madrid: Pedro Mora y Soler, 1845)...

19 Incluso mandos militares, por lo general críticos con la contribución de los milicianos, los alaban: Heraclio Alaiz, Manifiesto del brigadier D..., comandante militar que ha sido de la provincia de Lugo ... (A Coruña: Iguereta, 1823), 68. Con todo, no faltan tensiones respecto de la Milicia, como demuestra que el proyecto de reglamento de 1822 fuese objeto de repulsa generalizada: Ángel del Arenal, «Gobierno político de la provincia de Lugo» (Lugo, may. 8, 1822). La opinión de los realistas, obviamente, es muy distinta. Para uno catalán, los milicianos «Ya se ha visto lo que son, / sentina de corrupción, / abandono del trabajo, / y desde esto para abajo, / malos por toda razón»: Bruno de Lumeras, Apuntes poéticos y medios indispensables para que la empobrecida y desmoralizada España por sus apóstatas e hijos negros, vulgo liberales, comuneros, carbonarios y masones, logre recuperar su agonizante vida física y moral (Barcelona: Garriga y Aguasvivas, 1824). Otro, directamente, los tilda de asesinos: «Tot miliciano, crech, tenía licencia de assessinar sacerdots...»: F. J. P. D., Constitució sens máscara, o verdadera idea de la Constitució abortada en Cádiz lo any 1812... (Barcelona: Imprenta del Gobern, 1824), 32. Tampoco un cristino como Miraflores (Apuntes 109) la contempla con ojos favorables por su tendencia «revolucionaria». 
dudas respecto de su orientación política. ${ }^{20}$ No hay que olvidar que aquí se dan cita liberales convencidos, pero también cristinos que siguen a Isabel por fidelidad dinástica pero que no participan de un sentimiento liberal, y que entre los primeros oficiales de los urbanos no faltan individuos que lo habían sido de los Voluntarios Realistas de 1823-1833. La sombra de la amnistía a liberales y afrancesados extiende su manto sobre estos meses, pero también el discurso real de octubre de 1833 que llama a no realizar variaciones políticas en el país, en palabras de Zea Bermúdez, el presidente del gobierno a la muerte de Fernando VII, católico, monárquico y aferrado a sus leyes tradicionales. ${ }^{21}$

La unanimidad se empieza a romper en el verano de 1835, cuando muchas agrupaciones milicianas apoyan las insurrecciones contra el gobierno del Estatuto Real en reclamación de un marco legal más liberal, ${ }^{22}$ y desaparece ya casi definitivamente un año después con su repetición aumentada. ${ }^{23}$ Desde la ley se había intentado limitar el componente revolucionario de la milicia, pero la realidad aceleraba por la izquierda y las agrupaciones de urbanos y nacionales actuaban como cabezas de playa de un proyecto liberal al que el Estatuto no satisfacía. A partir de entonces la rama moderada de los liberales se aleja de la Nacional y ya no volverá a confiar en ella. ${ }^{24}$ Desde mediados de 1836 empieza a dibujarse su imagen como cuerpo armado de los progresistas que no tendrá retorno, ni siquiera en 1843 cuando apoye, en su mayoría, el golpe contra el otrora

20 Real decreto para la formación y alistamiento de la Milicia Urbana. (Madrid: Imprenta Real, 1834).

${ }^{21}$ Lo que se busca es «No la libertad loca, / no el bárbaro y sañudo desenfreno, / do con hedionda boca / derramó la discordia su veneno, / sino libertad pura / respirando la paz y la dulzura» («Al Estatuto Real», Santiago de Compostela, ab. 21, 1834: la referencia al Trienio de 1820-3 es evidente). Olvido y reconciliación se pide a los «Urbanos de Cristina», pero nada se explicita de caminar hacia un horizonte liberal: «reunir a todos sus hijos, hacer de ellos una familia de hermanos, quiere que olvidemos nuestros resentimientos personales ...» (Pedro Muñoz, Discurso que en la solemne función de la jura de nuestra augusta reina Doña María Isabel II... pronunció Don ... Barcelona: Garriga y Aguasvivas, 1834, 20). Como afirma Cristino Martos (La revolución de junio de 1854, Madrid: Colegio de Sordo-mudos y de Ciegos, 1854, X), en 1834 había muchos «absolutistas de Isabel II».

${ }^{22}$ Revista Española, ag. 16, 1835.

${ }^{23}$ Eco del Comercio, ag. 20, 1836.

${ }^{24}$ La «sargentada» de La Granja, en agosto de 1836, marca un momento de no retorno en la separación de los moderados de la Milicia, hasta el punto de que se integra como fecha de la memoria en su cultura política: Xosé Ramón Veiga, «El liberalismo conservador. Orden y libertad». La España liberal, 1833-1874. Eds. María Cruz Romeo y María Sierra (MadridZaragoza: Marcial Pons-PUZ, 2014), 289-316. 
tenido por uno de los suyos, el general Espartero, regente del Reino, en respuesta a lo que interpretan como una deriva autoritaria que se aleja de los preceptos del progresismo.

Inicialmente, la alianza antinatura entre moderados y progresistas antiesparteristas tiene entre sus objetivos la reorganización de la Milicia, que no su desaparición, pero la rápida evolución de los acontecimientos, que desembocan en un dominio conservador, lleva a su disolución en los primeros meses de $1844 .{ }^{25}$ La substituye en sus funciones de vigilancia la Guardia Civil, en lo que supone una suerte de deformación grotesca, de imitación a contrario, de némesis, que busca acabar con una institución revolucionaria e implantar otra más acorde con los tiempos postrevolucionarios alejada de cualquier veleidad popular y de toda intervención de los ayuntamientos. ${ }^{26}$ En el país que imaginan los moderados, con una participación popular muy restringida en lo público, no hay cabida para la ciudadanía armada sino para un cuerpo profesionalizado de disciplina militar con una rígida cadena de mando. ${ }^{27}$ La recuperación de la institución miliciana en 1854 se hace a regañadientes por la parte situada a la derecha de los revolucionarios, la que representa el general O’Donnell y un joven Antonio Cánovas, y será uno de los puntos de fricción entre los coaligados que contribuirá a su separación. Durante los dos años del Bienio la tendencia de la Milicia es a hacerse socialmente más abierta y políticamente más democrática, una evolución que la postrera recuperación de 1868 tiende a mantener e incluso acentuar. ${ }^{28} \mathrm{~A}$ estas alturas de la película, la visión de una milicia nacional como

\footnotetext{
${ }^{25}$ La evolución desde las posturas proclives a su reorganización hasta las que apuestan por la disolución, puede seguirse en los números de El Centinela de Galicia correspondientes a 1843 y 1844. En 29 de noviembre de 1843 apoyan su «urgente reorganización (porque) es más bien una institución anárquica, que una institución encargada del orden público», pero en 25 de marzo de 1844 prefieren suprimir los «17.000 milicianos armados» que hay en Galicia.

${ }^{26}$ Como dice enfático el capitán general de Galicia, Francisco Puig Samper, acabaron los «furores de la revolución» («Soldados, nacionales gallegos»: A Coruña, dic. 12, 1843).

27 Un moderado como Nicomedes-Pastor Díaz lo expresa claramente: «La ley empezaba, la revolución concluía...»: La cuestión electoral en diciembre de 1839 y enero de 1840 (Cáceres: Imprenta del Boletín, 1839), 17. Y otro, el Marqués de Miraflores (Memorias, III 29), sentencia que la Milicia es una «fuerza esencialmente peligrosa, como cualquiera otra con armas y en pleno uso del libre examen ...».

${ }^{28}$ La Oliva, abril 16, 1856. Las divergencias sobre qué debe ser y cómo se debe constituir la Milicia Nacional, se pueden seguir en los debates para la nueva ley (nonnata) que se desarrollan en 1856. Ver, Diario de Sesiones de las Cortes Constituyentes, números de junio de 1856.
} 
metáfora de la unión liberal ni siquiera es ya un recuerdo.

Junto de esta deriva temporal, la otra gran línea argumental identificable en los escritos contemporáneos sobre la Milicia es de tipo conceptual y valorativo. De manera simple, y desde una perspectiva conservadora, los nacionales se dividen en «buenos» y «malos», una distinción que con el tiempo ganará popularidad y audiencia también entre los progresistas «respetables» y «de orden» alejados de las tentaciones democráticas. Buenos son los milicianos que «tienen algo que perder», con propiedad, ocupación u oficio, que están dispuestos a la lucha por la libertad pero siempre dentro de un orden, con una conciencia clara de que los enemigos son los realistas y carlistas, y sin que tal defensa degenere en una situación de anarquía y de revolución permanente. Malos, en buena lógica, son los milicianos que proceden del lumpen, sin ocupación conocida o sospechosa de ser poco estable, los que nada tienen que perder y, supuestamente, se afilian para obtener alguna ventaja que les facilite su supervivencia. Estos son revolucionarios por defecto, dados a la lucha y la violencia, nada respetuosos con el derecho de propiedad privada y proclives a mantener un estado de constante profundización revolucionaria que, inevitablemente, deriva en anarquía y en inestabilidad social. ${ }^{29}$

En tanto que la Milicia sirve como auxilio armado en la lucha contra el carlismo, las valoraciones que recibe son positivas. Resulta un ejemplo de sacrificio por la patria liberal en construcción y de lucha contra el «otro», el enemigo al que incluso se despoja de su españolidad. Su participación, ordenada y obediente, es imprescindible para desarrollar e implantar la revolución que progresistas, pero también moderados, entienden tan necesaria como inevitable. Por lo menos hasta 1839 (en otras versiones, hasta 1837), todos son revolucionarios, todos luchan por derrotar al absolutismo y establecer un régimen liberal, y en ese todos los nacionales ocupan la primera posición del pódium. Cierto que, en opinión de algunos, ya han dado muestras, en los veranos

29 Ruiz de Morales; El Centinela de Galicia, nov. 11 y 20, 1843 (en el primer caso alaban a los nacionales de Lugo porque son "gente sensata, y poco aficionada a representar en la plaza», y en el segundo denigran a los de Monforte por proceder de la «hez» de la sociedad y actuar como «sans culottes»); Boletín de Noticias, dic. 12, 1843; La Oliva, ab. 16, 1856; jul. 23 y 30, 1856; ag. 9 y 27, 1856; Santillán 243, 256, 266, 401-2 (en 1854 entra en la Milicia Nacional «lo más abyecto de la plebe», «las gentes más peligrosas»), 409. 
de 1835 y 1836, de una desasosegante tendencia hacia la acción revolucionaria autónoma y directa, pero todavía en el fiel de la balanza pesa más su contribución en el combate a los partidarios de don Carlos.

Con el remate de la guerra civil de los siete años todo cambia. Los moderados entienden que la revolución ha terminado y que es hora de comenzar la construcción de una administración estatal aplazada por las necesidades de la lucha (Pro, 2019). Toca colgar fusiles y cananas, trabajar, ahorrar y enriquecerse (por lo menos, en la visión del francés Guizot),30 dar un paso atrás en la abrumadora presencia popular en el transcurrir político, adelgazar la esfera pública y, en suma, dejar hacer a la postrevolución. Los buenos milicianos ya han finalizado su trabajo. Pero no todos comparten el diagnóstico. Ni la mayoría del progresismo ni, sobre todo, las propias organizaciones milicianas están por la labor. La revolución, entienden, todavía no ha terminado su obra, aún necesita del plus de energía del ciudadano armado. Los carlistas han sido derrotados, pero ahora toca alzar sobre esta victoria y sobre la Constitución de 1837 los cimientos del país, lo que para ellos no pasa por su retirada a los cuarteles de invierno para dejar un espacio libre que ocupe el ordeno y mando de una administración centralizada que los moderados desean pero que los progresistas temen, porque creen que con ella las libertades tan duramente conquistadas darán un paso atrás. La polémica sobre la ley de ayuntamientos es la prueba del algodón, y la respuesta de la Milicia será apoyar con sus armas el golpe progresista contra los intentos centralizadores del último gobierno de María Cristina, que llevará al neoprogresista general Espartero a substituirla como regente del Reino. ${ }^{31}$

Lo que está en juego a partir de 1839 es el papel político futuro de la Milicia. Desde un punto de vista militar ya no es necesaria, y por lo tanto el debate

30 «Enrichissez-vous par le travail e par l'épargne», habría dicho el conocido político francés.

${ }^{31}$ Adrian Shubert, Espartero, el Pacificador. (Barcelona: Galaxia Gutenberg, 2018); Wladimiro Adame de Heu, Sobre los orígenes del liberalismo histórico consolidado en España (1835-1840). (Sevilla: Universidad, 1997); Isabel Burdiel, Isabel II. Una biografía (1830-1904) (Madrid: Taurus, 2010); Pedro Díaz Marín, La monarquía tutelada. El progresismo durante la regencia de Espartero (1840-1843). (Alacant: Universitat, 2015); Luis Garrido Muro, Guerra y paz. Espartero durante la Regencia de María Cristina de Borbón. (Madrid: CEPC, 2016); Javier Pérez Núñez. «La revolución de 1840: la culminación del Madrid progresista», Cuadernos de historia contemporánea. 36 (2014): 141-164; Jordi Roca, «Las fiestas cívicas del Trienio Progresista (18401843): progresistas enfrentados y desafío a la Regencia», Historia Contemporánea.56 (2018): 745 . 
se traslada a su protagonismo en la esfera pública, a su presencia como factor influyente en la singladura política del país: directamente en el nivel local, y de manera más lateral en el estatal al aparecer como el gran hermano siempre vigilante (y amenazante) ante cualquier desviación del camino. Estará atenta, sobre todo, a evitar toda tentación de autoritarismo y de comportamiento despótico de parte del poder ejecutivo y de rebajar el papel de las Cortes, una partitura que se toma muy en serio como demuestra su apoyo decisivo al final violento de la regencia de Espartero en 1843, acusado precisamente de comportamiento arbitrario y contrario al orden constitucional. No es, desde luego, una institución que pueda tomarse a broma, con los 300.000 milicianos, muchos armados, que hay ese año. ${ }^{32}$

Pero este papel político es difícil de defender y de argumentar en plena era postrevolucionaria, cuando la relación con lo público se intenta restringir a lo meramente individual y a la «calidad» socioeconómica concreta de cada individuo, idealmente plasmada en el acceso censatario al sufragio, una función antes que un derecho y, sobre todo, una atribución singularizada que contrasta con la presencia pública colectiva que adopta la Milicia Nacional. Su propio funcionamiento democrático, con la elección de los oficiales por los alistados y la existencia de penas iguales para mandos y milicianos rasos, y la posibilidad de un alistamiento socialmente muy abierto durante muchos momentos, choca de frente con las prácticas de restricción del sufragio dominantes hasta la implantación del universal masculino con la revolución de 1868. Y lo mismo sucede con su dependencia de los ayuntamientos, en unos tiempos que abogan por la centralización y por la fijación de una estructura administrativa en que las corporaciones locales pierden sus atribuciones políticas y pasan a ser el último eslabón de una cadena que los conecta con Madrid en una línea vertical y jerárquica. Que muchos liberales «respetables», no pocos progresistas de larga

${ }^{2}$ El Centinela de Galicia, nov. 11, 1843. La distribución de armas a semejante cantidad de civiles fue siempre un tema peliagudo, por el temor de que pudiesen volverse contra los mismos que las proporcionaban. El pueblo armado puede ser un desiderátum para el ala más demócrata y radical del progresismo, pero también un peligro que el liberalismo de notables cada vez lleva peor. Lo expresa con claridad Manuel Latre, capitán general de Galicia en 1836 (Comunicado, A Coruña, ab. 20, 1836): solo hay que repartir armamento entre gentes «que tenían algo que perder», porque de lo contrario acabarán fácilmente en manos de los carlistas. También su homónimo Laureano Sanz en 1839 (Circular, Santiago de Compostela, jun. 16, 1839): en la organización de la Milicia Nacional el aspecto a cuidar más es «tener seguras las armas». 
trayectoria, a la altura de 1856 estén por el diseño de una Milicia con exigencias duras para alistarse, es todo un indicio de por dónde caminan los tiempos. 33

\section{4. ¿Solo urbana? Aproximación a la realidad miliciana gallega}

De forma explícita o implícita, la Milicia Nacional siempre se ha pensado como una institución urbana. En las leyes y reglamentos que la configuran esta caracterización es la que, en general, ha prevalecido. En 1834 incluso su apellido es el de Urbana, como corresponde a que únicamente las localidades de más de 700 vecinos podían levantar compañías. Aquí funcionan dos perspectivas distintas pero complementarias. De un lado, las prevenciones de los liberales decimonónicos contra los rústicos, contra los habitantes de un ager que se imagina políticamente partidario de las opciones más cercanas a la tradición y a las fórmulas de gobierno absolutistas. Armarlos, en consecuencia, se presume peligroso, y de ahí la preferencia por potenciar la Milicia en espacios urbanizados, se entiende que más proclives a las políticas liberales, y esto aunque solo sea porque los principios del liberalismo se originan y se reproducen a partir de una cultura letrada que tiene su hábitat en las contadas ciudades. En parte, estamos ante prejuicios urbanitas, pero también es cierto que no les falta sustento real porque en las ciudades el liberalismo encuentra más fácil acomodo que fuera de ellas. Por otro lado, actúan las propias ideas previas de algunos historiadores cercanos, o influidos, por los preceptos de la teoría de la modernización, que contempla el progreso, también el político, como resultado de una vía de dirección única que de las ciudades llega hasta el campo.

Las dos perspectivas empujan en un mismo sentido, pero pueden y deben impugnarse en lo que tienen de absolutas, y esto es lo que se busca con el análisis del caso gallego. Partir, para la primera mitad del XIX español (e incluso para todo

33 La Oliva, jun. 7 y 14, 1856. Como también lo es que un político y militar progresista como Evaristo San Miguel, en un discurso a la Milicia, ponga el acento en que los alistados deben mantenerse «entre la libertad y las leyes», y actuar contra el «despotismo» lo mismo que contra la «licencia». En otras palabras: nada de adjudicarse el papel de suprema guardadora de las esencias liberales, que para eso ya están las leyes y los legisladores, no los civiles armados. Ver, $E l$ Libre Pontevedrés, sep. 29, 1854. Por no hablar de que, entre los propios protagonistas del golpe de 1854, el ala situada más a la derecha solo transige a regañadientes con el restablecimiento de la Nacional. Frente a ellos, sin embargo, se sitúan los que pretenden su robustecimiento, caso de un Nicolás María Rivero que la quiere situar fuera de las manos del ejecutivo, de forma que su disolución solo puedan decretarla las Cortes: Diario de Sesiones de las Cortes Constituyentes, en. 26, 1855: 1667; jun. 14, 1855: 5623-4. 
el siglo), de una distinción neta entre rural y urbano es más un deseo, o un espejismo, que una realidad. Aplicarlo a casos de población tan dispersa como la gallega carece por completo de sentido, lo mismo que para otras geografías que comparten esta característica de la escasa concentración poblacional. Lo que se da mayoritariamente es una suerte de continuum rural que encuentra algunos enclaves de mayor densidad de población, pero que no pasan de oasis contados en los que, además, el campo se introduce por doquier. Las villas, las cabezas de partido judicial creadas a partir de finales de 1833, e incluso las capitales provinciales, constituyen estos espacios que más que separar lo que hacen es servir de nexo central y organizador de los territorios en que se ubican. No se trata, en absoluto, de compartimentos estancos sino muy porosos, de forma que también en la constitución de sus milicias ese campo se va a colar y se va a dejar sentir.

De otro lado, y adopto ahora la perspectiva del investigador formado en historia agraria, es evidente que a estas alturas la teoría de la modernización ha demostrado sus limitaciones y puesto de manifiesto su incapacidad para explicar la trayectoria política de los espacios agrarios, mucho más complejos y llenos de política (permítaseme la expresión) de lo que imaginaban desde las universidades estadounidenses. Investigaciones como las de James C. Scott lo pusieron de manifiesto hace años, y su estela la han seguido numerosos historiadores. Nada queda ya, excepto en aproximaciones rancias y obsoletas, de una visión del agro como área huérfana de política y resignada a recibir el maná redentor llegado de la urbe, de hoja en blanco disponible para que cualquier escribano la cubra con una mal trazada caligrafía. Bien al contrario, lo que alumbran los estudios son unos espacios agrarios dotados de cultura política propia y, sobre todo, en absoluto inanes y complacientes ante interferencias y dictados llegados del exterior, sino vitales y dados a la réplica o, en todo caso, a la negociación que permita la recepción mediada de las novedades. En suma, una relación de arriba abajo pero también de abajo arriba. 34

34 James C. Scott, Weapons of the Weak. Everyday Forms of Peasant Resistance. (New Haven: Yale U.P., 1985); Los dominados y el arte de la resistencia. (Tafalla: Txalaparta, 2003); Domingo Gallego, Iñaki Iriarte y José Manuel Lana, «Las Españas rurales y el Estado, 1800-1931». Sombras del progreso. Las huellas de la historia agraria. Ed. Ricardo Robledo (Barcelona: Crítica, 2010), 85-116; Miguel Cabo y Xosé Ramón Veiga, «La politización del campesinado en la 
En Galicia, la presencia de milicianos de la Nacional es una constante desde el Trienio Liberal, y no únicamente en los contados espacios urbanos. Las razones para alistarse y servir como voluntario son variadas y hasta contradictorias entre sí. Por patriotismo, por fidelidad dinástica a Cristina e Isabel, por convicciones liberales, para evitar ser filiado en el ejército, para conseguir ventajas fiscales, para reunir méritos en el escalafón de empleados estatales, para mantener o conseguir un puesto público, para hacer carrera política, para congraciarse con las autoridades liberales, para portar armas y tener «autoridad». En el caso de los milicianos «forzosos», «locales» o «legales», la inscripción era obligatoria, e intentar evitarla suponía el pago de una pensión mensual para contribuir a los gastos de la institución. Bien es cierto que quedaba en manos de las autoridades locales definir una mayor o menor exigencia en la afiliación, en el cumplimiento de los deberes milicianos, en la actividad de las compañías y en el cobro de las pensiones, y que por sus propias características de institución civil, la disciplina no era comparable a la del ejército y, por ello, las posibilidades de tener un servicio relajado, poco exigente y hasta un punto desganado estaban ahí según las intenciones y las posibilidades de cada miliciano. Todo esto es cierto, y la variabilidad de situaciones es claro que dificulta ofrecer una foto unitaria, porque además unos contextos cambiantes introducen complejidad en el tema: no es lo mismo, por ejemplo, alistarse como miliciano en una Catalunya llena de carlistas en 1837 y conociendo que las posibilidades de servir en el frente son muchas, que hacerlo en 1854 sin estos condicionantes.

Pero con independencia de esta casuística, lo que también parece claro es que las consecuencias de servir en la Nacional, en especial como voluntario, son evidentes y que, como mínimo desde 1823, nadie puede llevarse a engaño. Se trata

época de la Restauración. Una perspectiva europea». La España rural, siglos XIX y XX. Aspectos políticos, sociales y culturales. Eds. Teresa M. Ortega y Francisco Cobo (Granada: Comares, 2011), 21-58; «Historia política en el mundo rural» (de próxima aparición en la editorial Comares); «James C. Scott y los dominados». Historia Social (Dossier).77 (2013). Coords. Ana Cabana y Miguel Cabo; «Democracia y mundo rural en España». Ayer (Dossier).89 (2013). Eds. Antonio Herrera y John Markoff; Xosé Ramón Veiga, «Estado y caciquismos en la España liberal, 1808-1876». El Estado desde la sociedad. Espacios de poder en la España del siglo XIX. Eds. Salvador Calatayud, Jesús Millán y María Cruz Romeo (Alacant: Universitat, 2016), 41-80; «La cultura local». Alcores (Dossier).3 (2007). Ed. Pedro Carasa; Óscar Bascuñán, Campesinos rebeldes. Las luchas del campesinado entre la modernidad y la globalización (Madrid: Los libros de la Catarata, 2009). 
de un compromiso que implica un posicionamiento ante la opinión pública explícito, que no se puede ocultar y que supone no únicamente una opción individual sino familiar, porque es toda la familia del miliciano la que queda marcada como liberal. La represión que padecen con el retorno del absolutismo entre 1823 y 1833 es muy fuerte y deja una huella profunda, de forma que servir en la Milicia a partir de 1834 supone tanto una promesa de futuro como una posibilidad de volver a padecer las consecuencias de un cambio de tornas políticas. Su cada vez mayor coloración progresista, y hasta demócrata a partir de 1854, la convierte igualmente en una apuesta arriesgada ante situaciones de dominio moderadas. 35 En suma, ser miliciano tiene hondas implicaciones tanto de carácter político como social y hasta económico (el tiempo invertido en el servicio se pierde en las ocupaciones diarias), y por lo tanto hay que otorgarle valor al compromiso que supone el formar en las filas de la Nacional.

En contra de una idea todavía vigorosa, milicianos nacionales no los hubo únicamente en las principales ciudades del país y en sus capitales de provincia. El caso gallego en el Trienio de 1820-1823 demuestra que, al contrario, la institución tuvo presencia y actividad en todos los rincones de la geografía, con un desarrollo especialmente marcado y lleno de significados en las villas que organizan el territorio y que ofrecen servicios a amplios hinterlands rurales. Mejor o peor armados y uniformados, más o menos municionados, con más o menos integrantes, con una mayor o menor actividad, lo cierto es que la figura del civil armado disciplinado a partir del reglamento miliciano ocupa el espacio público, y su presencia supone un paso en el proceso de socialización y de politización liberal de la población. El pueblo liberal tiene en ellos sus mejores y más decididos representantes, y por eso los realistas los convierten en sus dianas preferidas contra las que dirigen insultos, agresiones y disparos. 36

\footnotetext{
35 Ruiz de Morales 13, 17.

${ }^{36}$ Xosé Ramón Veiga, «Entre las bayonetas y la fiesta: Milicia Nacional, celebraciones patrióticas y construcción de la nación española en Galicia, 1808-1856». Nuevos horizontes del pasado. Culturas políticas, identidades y formas de representación. Eds. A. Barrio, J. de Hoyos y R. Saavedra (Santander: Universidad, 2011; edición en CD); «La Milicia Nacional como espacio de politización liberal en Galicia (1820-1844)». International Conference Old and New Worlds: the Global Challenges of Rural History. (Lisboa, 27-30 de enero de 2016); Poder e política na Galiza vilega, 179o-1833. Provincias de Lugo e Mondoñedo. (Santiago de Compostela: Bolanda, 2017); «Polo chan. Política e politización nos espazos locais, 1820-1823» (en prensa).
} 
Compañías milicianas aparecen en todas las capitales provinciales, en las villas que combinan ruralidad con una todavía incipiente urbanización y, también, en áreas que solo pueden definirse como aldeas. Cualquiera que conozca mínimamente la realidad demográfica gallega en la primera mitad del XIX, convendrá en que la presencia de espacios urbanos es escasa y, además, en que se trata de poblaciones en las que el campo se cuela por todas partes (Alonso, 2005). La mayoría del territorio se ocupa por un poblamiento continuo pero muy disperso, sin apenas concentraciones que merezcan el título de urbanas, y aun así la Nacional encuentra un caldo de cultivo en el que desarrollarse, señal de que la cultura política liberal avanza, de que tiene su público y de que las nuevas ideas, todavía no mayoritarias entre la población, sí encuentran acomodo en un número no despreciable de ciudadanos, otros tantos voceros de principios que contrastan tanto con la cultura política tradicional como con el ideario de realistas y absolutistas cuya fuerza en absoluto cabe despreciar. 37

Los diez años que transcurren entre 1833 y 1843 son políticamente muy agitados, y esto se traduce en una trayectoria cambiante y variable para los nacionales gallegos. Resulta visible que es la conformación concreta de los ayuntamientos, su mayor o menor querencia hacia lo que significa la Nacional, el determinante más influyente en su dinámica y su vitalidad. Más allá de una legislación común para todo el Estado, son las combinaciones locales del poder político las que, en última instancia, explican que haya más o menos compañías, que estén bien armadas, que cuenten con financiación, que se cobren las pensiones a los exceptuados y que presten servicios activos y continuos, así como la presencia de elementos locales que alienten su formación (el papel, mal conocido, de los nuevos jueces de primera instancia, por ejemplo). Lo dice con mucha claridad la Memoria que da cuenta de la trayectoria de la Milicia en la

\footnotetext{
37 Entre 1820 y 1823, como mínimo, hay compañías de milicianos en A Coruña, Ferrol, Santiago de Compostela, Arteixo, Narón, Betanzos, Fene, Mugardos, Padrón y Pontedeume (en la provincia de A Coruña); Lugo, Ribadeo, Viveiro, Mondoñedo, Sarria, A Fonsagrada, Burón, Sargadelos, Miranda, Castro de Rei, Póboa de Brollón, Lourenzá, O Valadouro, Viloalle, Abadín, Portocelo, Pobra de San Xiao, Monforte, Chantada, O Páramo, Portomarín, Cervantes y Ferreira de Pallares (en Lugo); Ourense, O Barco, Monterrei, Rúa de Petín, A Mesquita, Ribadavia, Verín, Boborás, Vilamarín, Paradalaviote, O Carballiño, O Ribeiro, Muíños, Beade, Maceda y Viana do Bolo (en Ourense); Vigo, Pontevedra, Ponteareas, Tui, Vilagarcía, Vilanova, Baiona (en Vigo). Como mínimo, porque no pocas agrupaciones permanecen ocultas al no tener presencia en la prensa de la época, y solo salen a la luz luego de laboriosos repasos por los archivos municipales de los más de 300 ayuntamientos gallegos. Ver, Veiga, 2011, 2016, 2017 y en prensa.
} 
ciudad de Lugo, al indicar que los gobiernos de 1837 y 1838 la descuidaron procurando la elección de jefes que "conducían al batallón de Lugo a una lamentable disolución casi cierta...».38 También el examen de la documentación miliciana en Ribadeo, Mondoñedo, Viveiro o A Coruña permite constatar esta realidad de unas compañías en que su vitalidad guarda relación directa con el interés que se toman los respectivos concejos, y que son los de una coloración más progresista los que se afanan por fomentar y mantener una Milicia numerosa y brillante. El resultado es que, a la altura de 1840, había compañías en todos las capitales de provincia, en las poblaciones cabeza de partido judicial y, además, en otras localidades menores, que en conjunto permitían una cobertura casi total del territorio y atender con presteza las situaciones que requiriesen de su presencia. 39 Políticamente, y ya de manera definitiva, la Nacional aparecía como el brazo armado de los liberales de izquierda.

Se demuestra con claridad en septiembre de 1840, cuando los milicianos gallegos apoyan mayoritariamente el golpe encabezado por el general Espartero contra el gobierno moderado. Los nuevos ayuntamientos, de mayoría progresista, destinan entonces a la Milicia unos recursos hasta aquí racaneados. La afirmación del de Mondoñedo, que asegura proporcionará medios para que la Nacional luzca con esplendor, es un ejemplo que cunde, y tanto su armamento como su uniforme resultarán beneficiados, así como su composición con un expurgo para contar solo con los «verdaderos» liberales. ${ }^{40} \mathrm{Al}$ tiempo, sin embargo, las divisiones

38 «Memoria histórica de la Milicia Nacional de Lugo», ag. 2, 1841. Arquivo Histórico Provincial de Lugo (AHPL), Concello, Milicia Nacional, legajo 394. También, mar. 13, 1838. Otros ejemplos, en Arquivo Municipal de Viveiro (AMv), Concello, Actas, leg. 732-3, oc. 22, 1839; Arquivo Municipal de Mondoñedo (AMM), Servizos Militares, Milicia Nacional, leg. 1489, ene. 23, 1837.

39 El Conciso, números de 1837; Sanz; Arquivo da Deputación Provincial de Lugo (ADPL), Actas, leg. 3965-2, may. 5, 1837; Arquivo da Deputación Provincial de A Coruña (ADPC), Actas, leg. 667, en. 4, 1836; mar. 25, 1836; ag. 9, 1836; sep. 29, 1836; leg. 668, mar. 21, 1837. Solo en la provincia de Pontevedra, en octubre de 1837, hay en pie 58 batallones de Milicia Nacional (El Conciso, oct. 27,1837 ), mientras que en Ourense se organiza una compañía de nacionales movibles con 1.100 efectivos (jul. 18, 1837); Boletín Oficial de la Provincia de Lugo, jun. 12.1842. En Santiago de Compostela, en julio de 1836, había disponibles 700 nacionales armados para luchar contra las tropas del carlista Gómez: Salvador Bodaño, Compendiosa manifestación de hechos ocurridos en la ciudad de Santiago en los días 17, 18, 19, 20 y 21 de julio del año de 1836. (Santiago de Compostela, 1836: manuscrito). Como dice El Centinela de Galicia (feb. 26, 1844), «se alistó a toda gente, para formar siquiera un batallón en cada aldea». La Diputación coruñesa asegura que muchos de los alistados en 1836 son «labradore» (ADPC, leg. 667, sep. 29, 1836).

40 AMm, Milicia Nacional, leg. 1489, nov. 4, 1840; Boletín Oficial de la Provincia de Lugo: oct. 31, 1841; dic. 9, 1841; feb. 3, 1842; ab. 7, 1842; jun. 6, 1842; ene. 19, 1843; Boletín de Noticias, nov. 
políticas toman asiento en la institución, en absoluto inmune al clima de confrontación interna que se adueña de los progresistas, con la cada vez más evidente separación entre los apoyos del regente Espartero y los progresistas que le son contrarios por seguir, argumentan, una línea política autoritaria, personalista y sometida a los militares «ayacuchos». A finales de 1843 hay en Galicia más de 17.000 milicianos nacionales (300.00o en toda España), ${ }^{41}$ la mayoría armados y la mitad uniformados, pero también escindidos políticamente en dos. Buena parte de las compañías auxilian el golpe antiesparterista que dan los moderados juntos de progresistas descontentos con Espartero en el verano de 1843, pero tampoco faltan los que reaccionan con las armas contra la evolución promoderada de la coalición. El resto de la historia es conocida con el desarme de la Milicia Nacional, una institución sin sitio en un tiempo postrevolucionario que restringe la esfera pública y apuesta por la centralización administrativa en un contexto político «jibarizado» en que solo una minoría dispondrá de derecho a voto. $4^{2}$

Su reaparición en 1854, aceptada a regañadientes por los grupos más moderados de la coalición revolucionaria, no resulta sorprendente. La Nacional acude puntual a su cita con la revolución, y en Galicia, aún con pocas investigaciones, todo parece indicar que lo hace decidida aprovechando los vientos favorables generados en diputaciones y ayuntamientos 43 . Si a finales de 1843 varias agrupaciones milicianas le merecían a la prensa el apelativo de «sanculotes y jamancieros» por su liberalismo radical y su tendencia a la «anarquía» y la «democracia», 44 todo hace indicar que esta orientación favorable a postulados liberales de izquierda y hasta democráticos se repiten entre 1854 y

4, 1843; AHPL, Milicia Nacional, leg. 394, sep. 14, 1840; ADPL, leg. 3967-1, en. 26, 1841 y oct. 21 y 23, 1841; en. 21, 1842; mar. 2, 1842; oct. 26, 1842; leg. 3967-2, dic. 17, 1842.

${ }^{41}$ El Centinela de Galicia, nov. 1, 1843 y mar. 25, 1844.

42 El Centinela de Galicia, números de octubre de 1843 a marzo de 1844; Junta provisional de gobierno de la provincia de La Coruña. (A Coruña, jun. 20, 1843); Boletín de Noticias, ag. 5, 1843; oct. 25, 1843; nov. 11, 1843; dic. 10, 13 y 16, 1843; ADPL, leg. 3968-2, nov. 23, 1843; feb. 3, 1844.

43 Boletín Oficial de la Provincia de Lugo, jul. 25, 1854; oct. 2, 1854; ag. 22, 1855; dic. 14, 1855; feb. 27, 1856; mar. 17, 1856; Boletín Oficial de la Provincia de La Coruña, ag. 2, 1854; El Libre pontevedrés, ag. 13, 1854; La Oliva, mar. 1, 1856; may. 7, 10, 17, 28 y 31, 1856; jul. 30, 1856; ADPL, leg. 3969-4, ag. 29, 1854; leg. 3970-1, feb. 17, 1855; mar. 7 y 14, 1855; ag. 20, 1855; ADPC, leg. 676, sep. 11,1854 ; oct. 2,1854 ; jun. 8,1855 .

44 El Centinela de Galicia, dic. 9, 1843. 
1856,45 si bien faltan estudios que permitan presentar esta afirmación como algo más que una hipótesis de trabajo para futuras investigaciones.

\section{Conclusión}

Entre el elenco de actores del proceso de politización que se da en España en la primera mitad del XIX, la Milicia Nacional tiene un puesto de prima donna. En conjunto, ninguna institución como ella hizo real el ideal del ciudadano armado en defensa de las libertades, y ninguna tuvo una ocupación más intensa del espacio público. A nivel individual, son miles los políticos, de todos los niveles, que pasan por sus filas y que aprenden aquí lo que es defender las ideas con las armas en la mano.

Como a todos los instrumentos de politización y de nacionalización, no le faltaron taras, desde la integración de efectivos sospechosos de desafectos hasta las carencias de material y de financiación, por no hablar de que amplias capas de la población se mostraron reticentes y contrarias a su presencia. Su conversión en brazo armado del progresismo, en su día valorada como negativa, podemos por el contrario observarla hoy como un peldaño más en la construcción de una pluralidad que, contra lo que deseaban los primeros liberales unitarios, no suponía un paso atrás sino una deriva tan inevitable como necesaria en la erección de la modernidad política.

Su tradicional consideración urbana conviene ponerla en cuarentena, tanto porque la dualidad rural-urbano se ajusta mal a estas décadas como, también, porque los espacios rurales no fueron ajenos a la presencia de nacionales. El caso de Galicia, presentado aquí de manera muy sintética, es sintomático de esta realidad, y demuestra que tampoco en el ager faltaron agentes activos dispuestos a la lucha primero contra el realismo, luego contra el carlismo y, al final, en favor de un liberalismo cada vez más cercano a formulaciones democráticas (Peyrou, 2008).

45 Miraflores, Memorias 29, 34, 86; Boletín Oficial de la Provincia de Lugo, jun. 6, 1855; ag. 27, 1856. 


\section{Obras citadas}

\section{Fuentes}

\section{Prensa}

Boletín de Noticias (A Coruña)

Boletín Oficial de la Provincia de La Coruña

Boletín Oficial de la Provincia de Lugo

Boletín Oficial de la Provincia de Orense

Diario de Sesiones de las Cortes Constituyentes (Madrid, 1854-1856)

Eco del Comercio (Madrid)

El Centinela de Galicia (A Coruña)

El Conciso (A Coruña)

El Libre pontevedrés (Vigo)

La Oliva (Vigo)

Revista Española (Madrid)

\section{Archivos}

Arquivo Municipal de Ribadeo

Arquivo Histórico Provincial de Lugo

Arquivo Municipal de Viveiro

Arquivo Municipal de Mondoñedo

Arquivo Municipal de A Coruña

Arquivo da Deputación Provincial de Lugo

Arquivo da Deputación Provincial de A Coruña

\section{Secundarias}

Al Estatuto Real. Santiago de Compostela, ab. 21, 1834

Alaiz, Heraclio, Manifiesto del brigadier D..., comandante militar que ha sido de la provincia de Lugo... A Coruña: Iguereta, 1823

Alba, Leopoldo de, La revolución española en el siglo XIX. Madrid: Biblioteca Universal Económica, 1869

Alcalá Galiano, Antonio, Historia de las regencias (1833-1843). Pamplona: Urgoiti, 2008

Alcalá Galiano, Antonio, Recuerdos de un anciano. Madrid: Perlado y Cía., 1913

Ameller, Victoriano y Castillo, Mariano, Los mártires de la libertad española. Madrid: Luis García, 1853

Arenal, Ángel del, Gobierno político de la provincia de Lugo, mar. 8, 1822

Bodaño, Salvador, Compendiosa manifestación de hechos ocurridos en la ciudad 
de Santiago en los días 17, 18, 19, 20 y 21 de julio del año de 1836. Santiago de Compostela, 1836 (manuscrito)

Cabello, Francisco, Sta. Cruz, Francisco y Temprado, Ramón María, Historia de la guerra última en Aragón y Valencia. Zaragoza: Institución Fernando el Católico, 2006

Calderón, Estébanez, Mis memorias. Madrid: Tebas, 1975

Castillo, José del, Exclamaciones de un expatriado. Barcelona: Ramón Martín, 1833

Cervera, Antonio I., La voluntad nacional, cómo el pueblo espera que la interpreten las Cortes Constituyentes. Madrid: Tomás Núñez, 1854

Chao, Eduardo, Historia de la vida militar y política de Martín Zambrano. Madrid: P. Madoz y L. Sagasti, 1846

Cid, Manuel María, Discurso que en la solemnidad de la jura y bendición de la bandera del Batallón de la benemérita Milicia Nacional de Santiago pronunció... Santiago de Compostela: Fermín Campaña, 1837

Dembowski, Carlos, Dos años en España durante la Guerra Civil, 1838-1840. Barcelona: Crítica, 2008

Díaz, Nicomedes-Pastor, A la Corte y a los partidos. Madrid: Corrales y Cía., 1846

Díaz, Nicomedes-Pastor, La cuestión electoral en diciembre de 1839 y enero de 1840. Cáceres: Imprenta del Boletín, 1839

Escalera, Evaristo y González, Manuel, La España del siglo XIX. Sus hombres y acontecimientos más notables. Madrid: J.J. Martínez, 1864

Espoz y Mina, Francisco, Memorias. Madrid: Rivadeneyra, 1851-2

F.J.P.D., Constitució sens máscara, o verdadera idea de la Constitució abortada en Cádiz lo any 1812... Barcelona: Imprenta del Gobern, 1824

Fernández de Córdova, Fernando, Mis memorias íntimas. Madrid: Sucesores de Rivadeneyra, 1886

García Blanco, Antonio María, Resumen de un siglo. Osuna: M. Ledesma, 1887

Garrido, Fernando, La España contemporánea. Sus progresos materiales y morales en el siglo XIX. Barcelona: Salvador Manero, 1865

Gracia, Mariano, Memorias de un zaragozano (1850-1861). Zaragoza: Institución Fernando el Católico, 2013

Historia de la Milicia Nacional. Madrid: Benito Hortelano y Cía, 1845

La España del siglo XIX. Colección de conferencias históricas celebradas durante el curso 1885-6. Madrid: Antonio San Martín, 1886

La milicia ciudadana de Vitoria. Vitoria: Marquínez, 1937

Latre, Manuel, Comunicado. A Coruña, ab. 20, 1836

López Castrillón, Rosendo M., Las nueve vidas de la Casa de la Fuente de Riodecoba. Libro de memoria de una casa campesina de Asturias (15501864). Xixón: Muséu del Pueblu d'Asturies, 2018

Lumeras, Bruno de, Apuntes poéticos y medios indispensables para que la 
empobrecida y desmoralizada España por sus apóstatas e hijos negros, vulgo liberales, comuneros, carbonarios y masones, logre recuperar su agonizante vida física y moral Barcelona: Garriga y Aguasvivas, 1824

Martínez Villergas, Juan, Los políticos en camisa. Madrid: Imprenta del Siglo, 1845-7

Martos, Cristino, La revolución de junio de 1854. Madrid: Colegio de Sordomudos y de Ciegos, 1854

Milicia Popular: diario del $5^{\circ}$ Regimiento, 1936-1937. Barcelona: Hacer, 1977

Miraflores, marqués de, Apuntes histórico-críticos para escribir la Historia de España de la época desde 1820 a 1823. Londres: Ricardo Taylor, 1834

Miraflores, marqués de, Memorias del reinado de Isabel II. Madrid: Atlas, 1964, III

Miraflores, marqués de, Reseña histórico-crítica de la participación de los partidos políticos en los sucesos políticos de España en el siglo XIX. Madrid: Espinosa, 1863

Muñoz, Pedro, Discurso que en la solemne función de la jura de nuestra augusta reina Doña María Isabel II... pronunció Don... Barcelona: Garriga y Aguasvivas, 1834

Pirala, Antonio, Historia de la guerra civil y de los partidos liberal y carlista. Madrid: Mellado, 1856

Príncipe, Miguel A., Tirios y troyanos. Historia tragi-cómica-política de la España del siglo XIX. Madrid: Pedro Mora y Soler, 1845

Puig Samper, Francisco, «Soldados, nacionales gallegos». A Coruña, dic. 12, 1843

Real decreto para la formación y alistamiento de la Milicia Urbana. Madrid: Imprenta Real, 1834

Relación de los festejos con que el Primer Batallón de la Milicia Urbana de La Coruña celebra la bendición de su bandera... A Coruña: Boletín Provincial, 1834

Ruiz de Morales, Joaquín, Historia de la Milicia Nacional, desde su creación hasta nuestros días. Madrid: Repullés, 1855

Sáenz de Viniegra, Luisa, Vida del general D. José María Torrijos y Uriarte. Madrid: Minuesa, 1860

Santillán, Ramón, Memorias (1808-1856). Madrid: Tecnos, 1996

Sanz, Laureano, Circular. Santiago de Compostela, jun. 16, 1839

Vida militar y política de Espartero. Madrid: Benito Hortelano y Cía., 1844-5

Villalba Hervás, Miguel, Recuerdos de cinco lustros, 1843-1869. Madrid: La Guirnalda, 1896

\section{Bibliografía}

Adame de Heu, Wladimiro, Sobre los orígenes del liberalismo histórico consolidado en España (1835-1840). Sevilla: Universidad, 1997 
Albargonzález, Manuel, La Milicia Nacional: protagonista y víctima de la revolución liberal en España (1834-1837). Trabajo Fin de Máster, Madrid: UAM, 2015

Alonso, Luis, «La crisis de la economía tradicional: continuidad y cambio en la Galicia del siglo XIX». Historia contemporánea de Galicia. coords. Jesús de Juana y Julio Prada. Barcelona: Ariel, 2005. 33-55

Aquillué, Daniel, «La milicia democrática, 1834-1840». Pensar con la Historia desde el siglo XXI. eds. Pilar Folguera et al. Madrid: UAM, 2015. 3025-3041

Arnabat, Ramón, La revolució de 1820 i el Trienni Liberal a Catalunya. Vic: Eumo, 2001

Balboa, Xesús, «Quintos e prófugos: os galegos e o servicio militar no século XIX». Mentalidades colectivas e ideoloxías. eds. Xavier Castro y Jesús de Juana. Ourense: Deputación, 1991.51-71

Bascuñán, Óscar, Campesinos rebeldes. Las luchas del campesinado entre la modernidad y la globalización. Madrid: Los libros de la Catarata, 2009

Burdiel, Isabel, «Morir de éxito: el péndulo liberal y la revolución española del siglo XIX», Historia y Política.1 (1999): 181-203

Burdiel, Isabel, Isabel II. Una biografia (1830-1904). Madrid: Taurus, 2010

Caballero, Margarita y Romero, Carmelo, «Oligarquía y caciquismo durante el reinado de Isabel II (1833-1868)», Historia Agraria.38 (2006): 7-26

Cabana, Ana; Miguel Cabo et al. «James C. Scott y los dominados». Historia Social N ${ }^{\circ}$ 77, (Dossier). Ana Cabana y Miguel Cabo (coords.), 2013.

Cabo, Miguel y Veiga, Xosé Ramón, «Historia política en el mundo rural» (de próxima aparición en la editorial Comares)

Cabo, Miguel y Veiga, Xosé Ramón, «La politización del campesinado en la época de la Restauración. Una perspectiva europea». La España rural, siglos XIX y XX. Aspectos políticos, sociales y culturales. eds. Teresa M. Ortega y Francisco Cobo. Granada: Comares, 2011. 21-58

Calatayud, Salvador, Millán, Jesús y Romeo, María Cruz, eds. El Estado desde la sociedad. Espacios de poder en la España del siglo XIX. Alacant: Universitat, 2016

Calatayud, Salvador, Millán, Jesús y Romeo, María Cruz, eds. Estado y periferias en la España del siglo XIX. Nuevos enfoques. València: PUV, 2009

Calles, Claudio, La Milicia Nacional en Salamanca durante el Trienio Liberal (1820-1823), Tesis doctoral, Salamanca: Universidad de Salamanca, 2015

Capdevila María, Carmen y Casals, Quintí, «Artesanos y campesinos en la Milicia Nacional de Lleida en la primera mitad del Ochocientos». Campesinos, artesanos, trabajadores. coords. Santiago Castillo y Roberto Fernández. Lleida: Milenio, 2001. 435-450

Carasa, Pedro et al. «La cultura local». Alcores, N. ${ }^{\circ}$ 3, (Dossier). Pedro Carasa (ed.), 2007.

Casals, Quintí, «Milicia Nacional, liberalismo y progresismo. El prototipo leridano en los primeros dos tercios del siglo XIX», Trienio.35 (2000): 117- 
154

Chust, Manuel, Ciudadanos en armas: la Milicia Nacional en el País Valenciano (1834-1840). València: Alfons el Magnànim, 1987

Díaz Marín, Pedro, La monarquía tutelada. El progresismo durante la regencia de Espartero (1840-1843). Alacant: Universitat, 2015

Domínguez, Manuel, «Salvación, unión e fraternidade: a Milicia Nacional de Pontedeume (1834-1844)», Cátedra. Revista eumesa de estudios.25 (2018): 299-332

Dueñas, Francisco, La Milicia Nacional Local en Barcelona durante el Trienio Liberal (1820-1823). Tesis doctoral, Barcelona: UAB, 1997

Esteban de Vega, Mariano, «El proceso de nacionalización española. Balance aproximativo de un proyecto». La nación omnipresente. Procesos de nacionalización en la España contemporánea. eds. Justo Beramendi, Miguel Cabo, Lourenzo Fernández y Alfonso Iglesias. Granada: Comares, 2020. IX-XXIV

Feijoo, Albino, Quintas y protesta social en el siglo XIX. Madrid: Ministerio de Defensa, 1996

Fernández Sebastián, Javier, coord. La aurora de la libertad. Los primeros liberalismos en el mundo iberoamericano. Madrid: Marcial Pons, 2012

Fernández Vargas, Valentina, Sangre o dinero. El mito del ejército nacional. Madrid: Alianza, 2004

Fontana, Josep, La epoca del liberalismo. Barcelona: Crítica-Marcial Pons, 2007

Frasquet, Ivana et al. «El Trienio Liberal. 200 años de constitucionalismo», Historia Constitucional N. ${ }^{\circ}$ 21. (Dossier). ed. Ivana Frasquet, 2020.

Freeden, Michael, Fernández Sebastián, Javier y Leonhard, Jörn, eds. In Search of European Liberalisms. Concepts, Languages, Ideologies. New York: Berghahn Books, 2019

Frieyro, Beatriz, Guerra, ejército y sociedad en el nacimiento de la España contemporánea. Madrid: Alianza, 2009

Gallego, Domingo, Iriarte, Iñaki y Lana, José Manuel, «Las Españas rurales y el Estado, 1800-1931». Sombras del progreso. Las huellas de la historia agraria. ed. Ricardo Robledo. Barcelona: Crítica, 2010. 85-116

García León, José María, La Milicia Nacional de Cádiz durante el Trienio Liberal, 1820-1823. Cádiz: Caja de Ahorros, 1983

Garrido Muro, Luis, Guerra y paz. Espartero durante la Regencia de María Cristina de Borbón. Madrid: CEPC, 2016

Gil Novales, Alberto, Las sociedades patrióticas (1820-1823). Las libertades de expresión y de reunión en el origen de los partidos políticos. Madrid: Tecnos, 1975

González, Óscar, «Hechos de la Milicia Nacional leonesa (1820-1823)». Las guerras en el primer tercio del siglo XIX en España y América, II. coord. Paulino Castañeda. Madrid: Deimos, 2005. 99-118

Guillén, Antonio, Una aproximación al Trienio Liberal en Almería. La Milicia 
Nacional Voluntaria y su entorno (1820-1823). Almería: IEA, 2000

Gutiérrez, Rosa Ana y Zurita, Rafael, «El Trienio Constitucional y la organización de la Milicia Nacional en Alicante (1820-1823)». La revolució francesa i el procés revolucionari a Catalunya i al País Valencià. Barcelona: UAB, 1999. 99-114

Hernández, Baldomero, La Milicia Nacional y las quintas en Mahón durante el Trienio Liberal. Es Castel: Museo Militar de Menorca y Patrimonio Histórico-Militar, 2009

Herrera, Antonio y John Markoff et al. «Democracia y mundo rural en España». Ayer (Dossier),89, Antonio Herrera y John Markoff (eds.), 2013.

Herrero, Guillermo, Liberalismo y Milicia Nacional en Pamplona durante el siglo XIX. Pamplona: UPN, 2003

La Parra, Emilio et al. El nacimiento de la política en España (1808-1869). Madrid: Editorial Pablo Iglesias, 2012

Luengo, Jorge, «La formación de la sociedad civil en la España del siglo XIX». Pensar el poder. Liber amicorum de Pedro Carasa. eds. Bartolomé Yun y Jorge Luengo. València: PUV, 2018. 77-96

Luis, Jean-Philippe. «Cuestiones sobre el origen de la modernidad política en España (finales del XVIII-1868)», Revista de historia Jerónimo Zurita.84, 2009, 247-278

Luis, Jean-Philippe y María Victoria López-Cordón et al. «La naissance de la politique moderne en Espagne (milieu XVIII siècle-milieu XIX siècle)», Mélanges de la Casa de Velázquez N. ${ }^{\circ}$ 35, V. 1. (Dossier). Jean-Philippe Luis y María Victoria López-Cordón (eds.), 2005.

Lyons, Martyn, Post-Revolutionary Europe, 1815-1856. Houndmills: Palgrave MacMillan, 2006

Millán, Jesús y Romeo, María Cruz, «Was the liberal revolution important to modern Spain? Political cultures and citizenship in Spanish history», Social History.29-3 (2004): 284-300

Millán, Jesús, «La formación de la España contemporánea: el agotamiento explicativo del fracaso liberal», Ayer.98 (2015): 243-256

Naranjo, Miguel Ángel, «La Milicia Nacional de Almendralejo», Revista de Estudios Extremeños.72 (2016): 639-684

Naranjo, Miguel Ángel, La Milicia Nacional de la ciudad de Badajoz y su marco provincial hasta su disolución de 1844. Badajoz: Diputación, 2008

Núñez, Xosé Manoel et al. «La construcción de la identidad regional en Europa y España (siglos XI y XX)». Ayer N. ${ }^{\circ}$ 64, (Dossier). Xosé-Manoel Núñez (ed.), 2006.

Palma, Luis F., «La Milicia Nacional de Lucena en el Trienio Esparterista», Crónica de Córdoba y sus pueblos.13 (2007): 323-338

París, Álvaro, «La Milicia Nacional» (inédito)

Peñalver, Luis F., «La revolución de 1854 y la formación de la Milicia Nacional. Talavera en el Bienio Progresista», Cuaderna.16-17 (2008-9): 77-116 
Pérez Garzón, Juan Sisinio, Milicia Nacional y revolución burguesa: el prototipo madrileño, 1808-1874. Madrid: CSIC, 1978

Pérez Núñez, Javier, «La revolución de 1840: la culminación del Madrid progresista», Cuadernos de historia contemporánea.36 (2014): 141-164

Portet, Joan, La Milícia Nacional de Vic durant la primera guerra carlina. Vic: PEO, 2003

Pro, Juan, La construcción del Estado en España. Una historia del siglo XIX. Madrid: Alianza, 2019

Ramón, José Antonio, «La Milicia Nacional de Fornela durante el Trienio Progresista (1840-1843)», Estudios Bercianos.39 (2015): 149-165

Riquer, Borja de, «Nacionalidades y regiones. Problemas y líneas de investigación en torno a la débil nacionalización española del siglo XIX». La Historia Contemporánea en España. eds. Antonio Morales y Mariano Esteban. Salamanca: Universidad, 1996. 73-92

Roca, Jordi, La Barcelona revolucionària i liberal: exaltats, milicians $i$ conspiradors. Barcelona: Fundació Noguera, 2011

Roca, Jordi, «Las fiestas cívicas del Trienio Progresista (1840-1843): progresistas enfrentados y desafío a la Regencia», Historia Contemporánea.56 (2018): 7-45

Rújula, Pedro y Chust, Manuel, El Trienio Liberal. Revolución e independencia (1820-1823). Madrid: Los Libros de la Catarata, 2019

Sánchez Carcelén, Antoni, «La formación de la Milicia Nacional en Lleida (18201821)175, Cuadernos de Historia Contemporánea.30 (2008): 251-271

Sánchez, F. X., «La Milícia Nacional d’Alcover durant el Trienni Liberal (18201823)», Butlletí del Centre d'Estudis Alcoverencs.78 (1997): 37-46

Santirso, Manuel, «Voluntarios realistas, voluntarios de Isabel II y milicia nacional, o en la guerra también hay clases (Cataluña, 1832-1837)», Historia Social.23 (1995): 21-40

Santos, Francisco, «La Ribera tudelana durante la Primera Guerra Carlista (18331839). El funcionamiento de la Milicia Urbana», Revista del Centro de Estudios Merindad de Tudela.6 (1994): 79-94

Scott, James C. Weapons of the Weak. Everyday Forms of Peasant Resistance. New Haven: Yale U. P., 1985

Scott, James C., Los dominados y el arte de la resistencia. Tafalla: Txalaparta, 2003

Shubert, Adrian, Espartero, el Pacificador. Barcelona: Galaxia Gutenberg, 2018

Sierra, María, Peña, María Antonia y Zurita, Rafael, Elegidos y elegibles. La representación parlamentaria en la cultura del liberalismo. Madrid: Marcial Pons, 2010

Sorando, Luis y Manzano, Antonio, «La Milicia Nacional de Zaragoza (18201823)», Emblemata.6 (2000): 177-212

Ureña, Mario, Regulación jurídica de la Milicia Nacional y su implementación en Castellón, Tesis doctoral, Castellón: UNED, 2004 
Urquijo, José Ramón, «¿Voluntarios o quintos? Reclutamiento y deserción en la primera Guerra Carlista». Violencias fratricidas. Carlistas y liberales en el siglo XIX. Pamplona: Príncipe de Viana, 2009. 99-186

Vallverdú, Robert, El suport de la Milícia Nacional a la revolució burgesa a Reus (1793-1876). Reus: AER, 1989

Veiga, Xosé Ramón, «El liberalismo conservador. Orden y libertad». La España liberal, 1833-1874. eds. María Cruz Romeo y María Sierra. MadridZaragoza: Marcial Pons-PUZ, 2014. 289-316.

Veiga, Xosé Ramón, «Entre las bayonetas y la fiesta: Milicia Nacional, celebraciones patrióticas y construcción de la nación española en Galicia, 1808-1856». Nuevos horizontes del pasado. Culturas políticas, identidades y formas de representación. eds. A. Barrio, J. de Hoyos y R. Saavedra. Santander: Universidad, 2011 (edición en CD)

Veiga, Xosé Ramón, «Estado y caciquismos en la España liberal, 1808-1876». El Estado desde la sociedad. Espacios de poder en la España del siglo XIX. eds. Salvador Calatayud, Jesús Millán y María Cruz Romeo. Alacant: Universitat, 2016. 41-80

Veiga, Xosé Ramón, «La Milicia Nacional como espacio de politización liberal en Galicia (1820-1844)». International Conference Old and New Worlds: the Global Challenges of Rural History. Lisboa, 27-30 de enero de 2016

Veiga, Xosé Ramón, «Polo chan. Política e politización nos espazos locais, 18201823» (en prensa)

Veiga, Xosé Ramón, Poder e política na Galiza vilega, 179o-1833. Provincias de Lugo e Mondoñedo. Santiago de Compostela: Bolanda, 2017 